\title{
Review
}

\section{What Have We Learned from Cerebrospinal Fluid Studies about Biomarkers for Detecting LRRK2 Parkinson's Disease Patients and Healthy Subjects with Parkinson's-Associated LRRK2 Mutations?}

\author{
David A. Loeffler ${ }^{\mathrm{a}, *}$, Jan O. Aasly ${ }^{\mathrm{b}}$, Peter A. LeWitt ${ }^{\mathrm{c}, \mathrm{d}}$ and Mary P. Coffey ${ }^{\mathrm{e}}$ \\ ${ }^{a}$ Department of Neurology, Beaumont Hospital-Royal Oak, Beaumont Health, Royal Oak, MI, USA \\ b Department of Neurology, St. Olav's Hospital, Trondheim, Norway \\ ${ }^{\mathrm{c}}$ Department of Neurology, Henry Ford Hospital, Detroit, MI, USA \\ ${ }^{\mathrm{d}}$ Department of Neurology, Wayne State University School of Medicine, Detroit, MI, USA \\ ${ }^{\mathrm{e}}$ Department of Biostatistics, Beaumont Hospital-Royal Oak, Beaumont Health, Royal Oak, MI, USA
}

Accepted 19 June 2019

\begin{abstract}
Mutations in the leucine-rich repeat kinase 2 (LRRK2) gene are the most common known cause of autosomal dominant Parkinson's disease (PD) and sporadic PD (sPD). The clinical presentation of LRRK2 PD is similar to sPD, and except for genetic testing, no biochemical or imaging markers can differentiate LRRK2 PD from SPD. Discovery of such biomarkers could indicate neuropathological mechanisms that are unique to or increased in LRRK2 PD. This review discusses findings in 17 LRRK2 - related CSF studies found on PubMed. Most of these studies compared analyte concentrations between four diagnostic groups: LRRK2 PD patients, sPD patients, asymptomatic control subjects carrying PD-associated LRRK2 mutations (LRRK2 CTL), and healthy control subjects lacking LRRK2 mutations (CTL). Analytes examined in these studies included A $\beta 1$-42, tau, $\alpha$-synuclein, oxidative stress markers, autophagy-related proteins, pteridines, neurotransmitter metabolites, exosomal LRRK2 protein, RNA species, inflammatory cytokines, mitochondrial DNA (mtDNA), and intermediary metabolites. FINDINGS: Pteridines, $\alpha$-synuclein, mtDNA, 5-hydroxyindolacetic acid, $\beta$-D-glucose, lamp2, interleukin- 8 , and vascular endothelial growth factor were suggested to differentiate LRRK2 PD from sPD patients; 8-hydroxy-2'-deoxyguanosine (8OHdG), 8-isoprostane (8-ISO), 2-hydroxybutyrate, mtDNA, lamp2, and neopterin may differentiate between LRRK2 CTL and LRRK2 PD subjects; and soluble oligomeric $\alpha$-synuclein, 8-OHdG, and 8-ISO might differentiate LRRK2 CTL from CTL subjects. CONCLUSIONS: The low numbers of investigations of each analyte, small sample sizes, and methodological differences limit conclusions that can be drawn from these studies. Further investigations are indicated to determine the validity of the analytes identified in these studies as possible biomarkers for LRRK2 PD patients and/or LRRK2 CTL subjects.
\end{abstract}

Keywords: Biomarkers, cerebrospinal fluid, mutation, Parkinson's disease

\footnotetext{
*Correspondence to: David A. Loeffler, DVM, PhD, Neurology Research Laboratory, Department of Neurology, Beaumont Hospital-Royal Oak, Beaumont Health System, 3601 West Thir-
} 


\section{INTRODUCTION}

Parkinson's disease (PD) is the second most common neurodegenerative disease, afflicting $1-2 \%$ of individuals over the age of 60 [1] and more than five million individuals worldwide [2]. PD's characteristic motor symptoms emerge after $50-70 \%$ of nigrostriatal dopaminergic neurons have been lost [3]. Current treatment options offer symptomatic relief but no neuroprotective or disease-modifying treatments are available. The NIH Biomarkers Working Group [4] defined "biomarker" as "a characteristic that is objectively measured and evaluated as an indicator of normal biological processes, pathogenic processes or pharmacologic response to a therapeutic intervention." Although potential clinical, biochemical, genetic, and imaging biomarkers for PD have been investigated for decades (see, for example, reviews by Haas et al. 2012 [5], LeWitt et al. 2013 [6], Magdalinou et al. 2014 [7], Delenclos et al. 2016 [8], Mollenhauer et al. 2017 [9], and Parnetti et al. 2019 [10]), currently there are no validated biomarkers to assist in diagnosing PD ("trait" biomarkers) or determining its neuropathological progression ("state" biomarkers). Recent investigations have revealed potential PD biomarkers which merit further study, including neurofilament light chain (NFL) [11] and aggregated $\alpha$-synuclein (particularly when measured by real-time quaking-induced conversion (RT-QuIC) assays [12-14]). The diagnosis of PD is based upon its characteristic motor symptoms of tremor, rigidity, bradykinesia, and balance abnormalities [15]. Although nonmotor symptoms such as rapid eye movement sleep behavioral disorder, olfactory deficits, depression, and problems with bowel function often precede PD's motor symptoms [8], these abnormalities are nonspecific so their presence does not facilitate early diagnosis of the disease. Because of similarities in clinical presentation between PD and atypical parkinsonian disorders such as multiple system atrophy (MSA), progressive supranuclear palsy (PSP), corticobasal degeneration (CBD), and dementia with Lewy bodies (DLB), accurate diagnosis of early-stage PD is difficult. Although experienced movement disorders specialists are typically able to distinguish PD from other parkinsonian disorders with $>85 \%$ accuracy, this figure is based on patients diagnosed with probable PD for more than five years; the diagnostic accuracy for patients with parkinsonian features at initial presentation is only about $26 \%$ [16]. In addition to facilitating the diagnosis of PD, a biomarker for early PD might be of value for identifying populations at risk for developing the disease [8]. Discovery of biomarkers accurately reflecting PD's progression should also improve the evaluation of disease-modifying (neuroprotective) therapies, once such therapies become available [17].

\section{ASSOCIATION OF LEUCINE-RICH REPEAT KINASE 2 (LRRK2) GENE MUTATIONS WITH PD}

Because etiological mechanisms and strong risk factors other than age are not known for PD, most cases of PD are referred to as idiopathic or sporadic PD (sPD). The 5-10\% of PD cases for which inherited patterns can be detected are thought to be due to gene mutations [18]. Mutations in the leucinerich repeat kinase 2 (LRRK2) gene are the most common known cause of both autosomal dominant PD and sPD [19]. The symptoms of patients with PD-associated LRRK2 mutations vary between families, and even within families, affected by the same mutation [20]. On an individual basis, the clinical presentation of LRRK2 PD is considered to be indistinguishable from that of SPD [20-24]. However, LRRK2 PD patients may have less non-motor symptoms than SPD patients [24] and neuropathological progression of LRRK2 PD, as measured by 6(18)F-fluoro-L-dopa positron emission tomography, may be slower than for sPD [25]. Neuropathological findings in LRRK2 PD are variable and may include $\alpha$-synuclein-containing Lewy bodies (LBs) within degenerating neurons in the substantia nigra pars compacta (SNC), tau pathology (neurofibrillary tangles [NFTs]), or loss of SNC neurons in the absence of detectable neuronal inclusions [26-31]. Wider et al. [32] reviewed postmortem findings in 38 patients (from 13 previously published studies) with "proven pathogenic" LRRK2 mutations. 28 of the patients had symptoms compatible with typical levodopa-responsive parkinsonism. Neuropathological findings in 20 of the subjects were similar to those typically found in idiopathic (sporadic) PD, with SNC LBs. Nigral degeneration without LBs was found in 12 patients, diffuse LB disease was present in two subjects, tau pathology was found in two subjects, and $\alpha$-synuclein-immunoreactive glial inclusions and ubiquitin-immunoreactive structures were found in one subject each. The range of neuropathological findings in LRRK2 PD might decrease the likelihood that $\alpha$-synuclein or tau concentrations in CSF 
or peripheral body fluids could offer biomarkers for LRRK2 PD's diagnosis or progression.

Asymptomatic control subjects carrying PDassociated LRRK2 mutations (hereafter, "LRRK2 CTL") are considered to be a "pre-clinical PD" cohort [33]. ${ }^{18 \mathrm{~F}-\text { fluoro-DOPA PET scans and dopamine }}$ transporter scans have detected reduced striatal dopamine neurotransmission in these individuals, compared to healthy control subjects without these mutations (hereafter, "CTL") [34, 35].

\section{SYSTEMIC BIOMARKERS FOR DETECTING LRRK2 PD AND LRRK2 CTL SUBJECTS}

CSF is the biological fluid closest to the brain [17] and changes in the levels of analytes in the brain are often reflected in CSF [8], making it a logical choice in which to search for biomarkers for neurodegenerative disorders. Nevertheless, because obtaining CSF is an invasive procedure, peripheral body fluids (primarily blood and urine) continue to be studied to determine if they may offer biomarkers for these disorders. A few potential biomarkers for LRRK2 PD have been identified to date in peripheral fluids. A recent study found increased ratios of phosphorylated LRRK2 to total LRRK2 in urinary exosomes from LRRK2 PD patients compared to sPD, LRRK2 CTL, and CTL subjects [36]. Exosomes are lipid bilayer-delimited vesicles secreted by cells, which contain cytosolic, endosomal, and plasma membrane proteins; they are useful for protein measurements in extracellular fluids because their proteins are protected by the exosome's lipid bilayer from degradation by phosphatases and proteases [37]. In a subsequent study [38], male LRRK2 PD patients were found to have higher urinary exosomal pS1292LRRK2 concentrations than LRRK2 CTL subjects, although the opposite trend was found in female subjects. In other investigations, serum platelet-derived growth factor was suggested to differentiate between LRRK2 PD and sPD patients [39], while serum interleukin-1 $\beta$ (IL-1 $\beta$ ) [39] and plasma urate [40] were suggested as potential peripheral biomarkers for LRRK2 CTL subjects. However, different findings for the latter two analytes were reported by other investigators; Johansen et al. [41] found no significant differences in plasma uric acid concentrations between LRRK2 CTL and CTL subjects, and Brockmann et al. [42] found similar serum levels of IL-1 $\beta$ and other inflammatory markers between LRRK2
CTL and CTL subjects. Fan et al. [43] measured LRRK2-induced phosphorylation of an endoplasmic reticulum-specific GTPase, Rab10 [44], in peripheral blood neutrophils from small numbers of PD patients and control subjects with or without the LRRK2 G2019S mutation (sPD = 7, LRRK2 PD = 5, LRRK2 $\mathrm{CTL}=1, \mathrm{CTL}=13$ ). LRRK2-mediated phosphorylation of Rab10 was detected in neutrophils from all study subjects, with no statistically significant differences between the groups (not surprising given the low group sizes). Based on these findings Fan et al. suggested that phosphorylated Rab10 might represent a peripheral biomarker for "patient stratification based on LRRK2 kinase activity."

\section{PD-ASSOCIATED LRRK2 GENE MUTATIONS}

The LRRK2 gene encodes a $286 \mathrm{kDa}$ multidomain peptide whose actions include neurite outgrowth, cytoskeletal maintenance, vesicle trafficking, regulation of autophagy, and immune functioning [45-49]. More than 100 LRRK2 gene variants have been reported [50], most of which are "rare orphan changes" (their significance is unknown) [51]. A number of LRRK2 mutations have been shown to be pathogenic for $\mathrm{PD}$; these mutations are in the gene's kinase, ROC (Ras of complex protein), and COR (C-terminal of Ras) domains [52-56]. A recent analysis concluded that the G2019S, G2385R, A419V, R1441C/G/H, and R1628P LRRK2 mutations were significantly associated with an increased risk for $\mathrm{PD}$, while the $\mathrm{R} 1398 \mathrm{H}$ mutation, located in the ROC domain, was associated with a significantly decreased risk for PD [57]. G2019S, considered to be the most common PD-associated "pathogenic substitution" LRRK2 mutation [51], increases LRRK2 protein's kinase (phosphorylation) activity [30, 53]. The frequency of this mutation is highest among Ashkenazi Jews and North African Arab-Berber populations [58, 59]; notably, about $15 \%$ of PD patients of Ashkenazic Jewish heritage carry this mutation $[59,60]$. Estimates of the lifetime penetrance of this mutation have varied from $22 \%$ to $100 \%$ [22, 23, 28, $58,59,61-63]$. A study co-authored by the International LRRK2 Consortium found the risk of PD for G2019S mutation carriers to be $28 \%$ at age 59 years, $51 \%$ at 69 years, and $74 \%$ at 79 years [28]. The discrepancies between the different estimates of the penetrance of G2019S may be due in part to different populations being studied; the highest estimates were 
from family studies, whereas lower estimates came from ethnically diverse PD populations not selected on the basis of familial history [63]. The G2385R and R1628P mutations are susceptibility (risk) variants, rather than penetrant variants, which are found in 3$4 \%$ of healthy individuals and 6-8\% of PD patients in some Asian populations $[64,65]$. Recent studies have shown that the G2385R mutation reduces LRRK2's kinase activity [66], as well as destabilizing LRRK2 and promoting its proteasomal degradation [67].

The G2019S mutation may play a role in $\alpha$ synuclein and/or tau pathology in LRRK2 PD, because $\alpha$-synuclein in LBs is extensively phosphorylated [68], and phosphorylated tau co-localizes with $\alpha$-synuclein in some LBs [69]. Phosphorylation is thought to increase tau's neurotoxicity [70] but the influence of phosphorylation on $\alpha$-synuclein's toxicity is unclear [71]. Although some studies have suggested that LRRK2 may phosphorylate $\alpha$ synuclein [72] and/or tau [73-75], the only presently accepted bona fide LRRK2 kinase substrates are LRRK2 protein itself and some Rab GTPases [76, 77] such as Rab10, as mentioned above.

\section{SIGNIFICANCE OF LRRK2 BIOMARKERS}

There are currently no accepted biomarkers for detecting PD in its preclinical stages in individuals bearing PD-associated LRRK2 mutations. Discovery of such biomarkers would allow initiation of neuroprotective therapies (once such therapies have been developed) early in the disease process before extensive loss of dopaminergic neurons has occurred. Further, although genotyping and information about a patient's family history can differentiate between LRRK2 PD and SPD, no biomarkers have been identified which can unequivocally do so. Because the pathogenic mechanisms responsible for loss of dopaminergic neurons in individuals with LRRK2 mutations may differ from those in SPD [78], effective therapies for slowing disease progression might also differ between LRRK2 PD and SPD. Biomarkers for assessing disease progression, which could be used to determine the effectiveness of neuroprotective strategies in clinical trials, might also differ between LRRK2 PD and SPD, so there is a need for developing biomarkers for LRRK2 PD's progression as well as for its early diagnosis.

Not all older individuals carrying PD-associated LRRK2 mutations develop PD, but determining which ones will do so is not possible at present. Discovery of biomarkers for differentiating LRRK2 PD from LRRK2 CTL subjects might facilitate earlier detection of PD in LRRK2 mutation carriers, increasing the chances that disease-modifying therapies (when available) might slow disease progression in these individuals.

Finally, although genotyping can determine if an individual is carrying a PD-associated LRRK2 mutation, discovery of CSF biomarkers which can distinguish between LRRK2 CTL and CTL subjects might provide clues about LRRK2 mutation-related changes in the brain that precede the clinical manifestations of PD.

\section{CSF STUDIES IN CARRIERS OF PD-ASSOCIATED LRRK2 MUTATIONS: ANALYTES, DIAGNOSTIC GROUPS, SUMMARY STATISTICS OF GROUPS IN EACH STUDY, AND NUMERIC SUMMARIES OF RESULTS}

Seventeen LRRK2-related CSF studies were found in PubMed using combinations of the terms "LRRK2," "Parkinson's," and "CSF." Most of the studies compared analyte concentrations between four diagnostic groups, namely SPD patients, LRRK2 PD patients, LRRK2 CTL subjects, and CTL subjects (who lacked LRRK2 gene mutations or, in some studies, lacked all known PD-associated gene mutations). G2019S was the most common LRRK2 mutation in the subjects in these studies. Table 1 indicates, for each study, analyte(s) measured, number of subjects in each group, mean age for each group, and percentage of males for each group. (The studies by Podlesniy et al. [78] and Vilas et al. [79], from the Institut d'Investigacions Biomediques de Barcelona and the University of Barcelona respectively, measured $A \beta 1-42$, tau, p-tau, and $\alpha$-synuclein in samples from the Michael J. Fox Foundation LRRK2 Cohort Consortium. It was unclear if some of the samples were used in both studies. Conversely, although the studies on pteridines by Koshiba et al. [80] and Ichinose et al. [81] were both performed at the Tokyo Institute of Technology, different samples were used in the two studies. Koshiba et al. used samples from carriers of the I2020T LRRK2 mutation, while Ichinose et al. used carriers of the G2019S or N1437H LRRK2 mutations.) Some studies lacked one or more of the four standard diagnostic groups. Tables 2 and 3 contain numeric summaries for each study, organized 
by analyte and diagnostic group. The main findings in each study will be summarized below, following an explanation of the rationale for investigating each analyte (or group of related analytes) as a possible LRRK2 PD or LRRK2 CTL biomarker.

\section{LRRK2 CSF STUDIES MEASURING Aß1-42, TOTAL TAU, AND PHOSPHORYLATED TAU}

$\mathrm{A} \beta$ and tau are the main components of senile plaques and NFTs respectively, the hallmark pathological findings in Alzheimer's disease (AD). A $\beta 1-42$ is the predominant $A \beta$ species in both sporadic and familial $\mathrm{AD}[82,83]$. Plaques and NFTs contain fibrillar $A \beta$ and tau respectively, formed when soluble oligomers of these proteins become sufficiently large to be insoluble. Because $A \beta$ is an extracellular protein, when it precipitates (and forms plaques) the concentration of soluble $A \beta$ in brain extracellular fluid and CSF decreases; thus, A $\beta 1-42$ is typically decreased in AD CSF [84]. Conversely, tau is an intracellular protein, found mainly in neurons (where it binds to tubulin, promoting tubulin's assembly into microtubules [85]), so its insoluble aggregates (NFTs) are intraneuronal. Increased phosphorylation of tau ("hyperphosphorylation") occurs in AD [86]. This process decreases its binding to tubulin [87], reducing intra-axonal transport of organelles and vesicles, with potential neurotoxic consequences. Increased phosphorylation of tau also facilitates its aggregation [88]. Degenerating neurons release tau into the extracellular space, and tau is also actively secreted by neurons $[89,90]$ although which tau species are secreted is unclear [91]. CSF concentrations of total and phosphorylated tau are typically elevated in AD [92]. Some studies have reported similar levels of CSF A $\beta$ between PD patients and control subjects, whereas others have found lower concentrations in PD [93]. Conflicting results have also been published for the comparison of CSF levels of total and phosphorylated tau between PD patients and control subjects [reviewed by Magdalinou et al. 2014 [7] and Jimenez-Jimenez et al. 2014 (93)].

Four LRRK2 CSF studies were found which measured $A \beta 1-42$, total tau, and phosphorylated (pS181) tau. An investigation by Aasly et al. [94] which included only LRRK2 PD and LRRK2 CTL subjects reported that the concentrations of all three proteins were lower in LRRK2 PD patients than in LRRK2 CTL subjects; although these findings were similar (i.e., in the same direction) to their earlier results in which the CSF concentrations of these proteins were found to be lower in SPD patients than in control subjects [95], none of these differences between the two groups achieved statistical significance. Brockmann et al. [96] measured these proteins in CSF (at "baseline" and at "followup," which was $24 \pm 6$ months after baseline) from LRRK2 PD patients (however, this group consisted of just five subjects), sPD patients, CTL subjects, and PD patients carrying mutations in the glucocerebrosidase (GBA) gene, which encodes for a lysosomal enzyme which is deficient in Gaucher disease [97]. GBA gene mutations have been associated with PD [98]. No statistically significant differences were found between the three PD groups for $\mathrm{A} \beta 1-42(p=0.30)$ although the three PD groups had lower A $\beta 1-42$ than the CTL group. Total and phosphorylated tau were reported to be lower in SPD and GBA PD patients than in CTL subjects. Podlesniy et al. [78] and Vilas et al. [79] measured $A \beta 1-42$, total tau, and phosphorylated tau in the four diagnostic groups and reported no statistically significant differences between groups for these analytes. (The $p$-value for the overall test of group differences for $A \beta 1-42$ in the study by Vilas et al. was 0.094, whereas Podlesniy et al. did not report $p$-values for these analytes, either for the overall test of group differences or for pairwise comparisons.) Taken together, these studies suggest that the presence of PD-associated LRRK2 mutations may cause little if any changes in CSF levels of A $\beta 1-42$, total tau, and phosphorylated tau.

\section{LRRK2 CSF STUDIES MEASURING $\alpha$-SYNUCLEIN}

$\alpha$-synuclein is the main protein in LBs, the intracellular inclusions which are typically detectable in approximately $10 \%$ of degenerating dopaminergic neurons in the PD SNC [99]. LBs contain fibrillar (insoluble) $\alpha$-synuclein. As with $A \beta$ and tau, soluble oligomeric $\alpha$-synuclein, rather than fibrillar $\alpha$-synuclein, is thought to be the most neurotoxic $\alpha$ synuclein conformation [100]. LB body formation may not contribute to neuronal death (and it may, in fact, be neuroprotective) $[101,102]$. $\alpha$-synuclein can be secreted by neurons [103], contributing to its presence in CSF [104]. Total and oligomeric $\alpha$-synuclein have been investigated as possible CSF biomarkers for PD in many studies; however, a recent metaanalysis of 34 such studies concluded that, although 
Table 1

Summary statistics for LRRK2 CSF studies

\begin{tabular}{|c|c|c|c|c|c|}
\hline Study & Analyte(s) & sPD & LRRK2 PD & LRRK2 CTL & CTL \\
\hline $\begin{array}{l}\text { Koshiba } 2011 \\
{[80]}\end{array}$ & $\begin{array}{c}\text { pteridines, } \\
\text { HVA, 5-HIAA }\end{array}$ & $\begin{array}{c}21 ; 72.4 \\
52 \%\end{array}$ & $7 ; 67.3 ; 14 \%$ & $2 ; 61.5 ; 100 \%$ & $21 ; 72.4 ; 52 \%$ \\
\hline $\begin{array}{l}\text { Aasly } 2012 \\
{[94]}\end{array}$ & $\begin{array}{c}\mathrm{A} \beta 1-42, \mathrm{tau} \\
\text { p-tau }\end{array}$ & $8 ; 67.3 ; 14 \%$ & $18 ; 51.3 ; 56 \%$ & & \\
\hline Shi [106] & $\alpha$-syn, DJ-1 & 8 & 18 & & \\
\hline $\begin{array}{l}\text { Fraser } 2013 \\
{[166]}\end{array}$ & $\begin{array}{l}\text { exosomal } \\
\text { LRRK2 }\end{array}$ & & & & $2^{\mathrm{a}}$ \\
\hline $\begin{array}{l}\text { Aasly } 2014 \\
\text { [109] }\end{array}$ & $\begin{array}{c}\text { total } \alpha \text {-syn, } \\
\alpha \text {-syn soluble } \\
\text { oligomers }\end{array}$ & $\begin{array}{c}35 ; 54 \\
92 \%\end{array}$ & $13 ; 64 ; 85 \%$ & $20 ; 55.4 ; 55 \%$ & $42 ; 59 ; 40 \%$ \\
\hline $\begin{array}{l}\text { Aasly } 2015 \\
{[168]}\end{array}$ & $\begin{array}{l}\text { intermediary } \\
\text { metabolites }\end{array}$ & $\begin{array}{c}17 ; 61.9 ; \\
76 \%\end{array}$ & $10 ; 70.4 ; 60 \%$ & $11 ; 63.4 ; 45 \%$ & $\begin{array}{c}19 ; 57.7 \\
53 \%\end{array}$ \\
\hline $\begin{array}{l}\text { Brockmann }{ }^{\mathrm{b}} \\
2015 \text { [96] }\end{array}$ & $\begin{array}{c}\mathrm{A} \beta 1-42, \text { tau } \\
\text { p-tau }\end{array}$ & $\begin{array}{c}30 ; 66.0 \\
73 \%\end{array}$ & $5 ; 59.0 ; 20 \%$ & & $\begin{array}{c}16 ; 65.5 \\
50 \%\end{array}$ \\
\hline $\begin{array}{l}\text { Stewart } 2015 \\
{[33]}\end{array}$ & p- $\alpha$-syn & $\begin{array}{l}\text { multicenter } \\
\text { cohort: } 209 \text {; } \\
65.9 ; 75 \% \text {; } \\
\text { DATATOP } \\
\text { cohort: } 95 \\
61.1 ; 63 \%\end{array}$ & $7^{\mathrm{c}}$ & $23^{c}$ & \\
\hline $\begin{array}{l}\text { Hossein- } \\
\text { Nezhad } 2016 \\
{[170]}\end{array}$ & RNA species & $27^{\mathrm{d}}$ & & & $30^{\mathrm{d}}$ \\
\hline $\begin{array}{l}\text { Loeffler } \\
2016 \text { [125] }\end{array}$ & $\begin{array}{l}\text { Nrf2, } \\
\text { HSPA8 }\end{array}$ & $\begin{array}{c}60 ; 58.5 \\
70 \%\end{array}$ & $10 ; 60.7 ; 20 \%$ & $31 ; 54.1 ; 61 \%$ & $\begin{array}{c}23 ; 61.7 \\
39 \%\end{array}$ \\
\hline $\begin{array}{l}\text { Podlesniy } \\
2016 \text { [78] }\end{array}$ & $\begin{array}{c}\text { A } \beta 1-42 \\
\text { tau, p-tau, } \\
\alpha-\text {-syn, } \\
\text { mtDNA }\end{array}$ & $\begin{array}{c}31 ; 58 \\
68 \%\end{array}$ & $20 ; 64 ; 45 \%$ & $26 ; 52 ; 62 \%$ & $21 ; 54 ; 52 \%$ \\
\hline $\begin{array}{l}\text { Vilas } 2016 \\
\text { [79] }\end{array}$ & $\begin{array}{l}\text { A } \beta 1-42, \text { tau, } \\
\text { p-tau, } \alpha-\text { syn }\end{array}$ & $\begin{array}{c}35 ; 60 \\
71 \%\end{array}$ & $28 ; 65 ; 46 \%$ & $41 ; 53 ; 51 \%$ & $\begin{array}{c}34 ; 55 \\
44 \%\end{array}$ \\
\hline $\begin{array}{l}\text { Loeffler } \\
2017 \text { [127] }\end{array}$ & $\begin{array}{l}\text { 8-OHdG, } \\
\text { 8-ISO, TAC }\end{array}$ & $\begin{array}{c}31 ; 60.5 \\
48 \%\end{array}$ & $19 ; 61.4 ; 21 \%$ & $\begin{array}{c}30 ; 62.3 \\
40 \%\end{array}$ & $\begin{array}{c}27 ; 61.5 \\
37 \%\end{array}$ \\
\hline $\begin{array}{l}\text { Wang } 2017 \\
{[38]}\end{array}$ & $\begin{array}{l}\text { exosomal } \\
\text { LRRK2 }\end{array}$ & $\begin{array}{c}19 ; 60 \\
58 \%\end{array}$ & $19 ; 57 ; 16 \%$ & $\begin{array}{c}39 ; 63 \\
33 \%\end{array}$ & $5 ; 60 ; 0 \%$ \\
\hline $\begin{array}{l}\text { Ichinose } \\
2018[81]\end{array}$ & pteridines & $\begin{array}{c}46 ; 57.3 \\
76 \%\end{array}$ & $13 ; 61.5 ; 46 \%$ & $\begin{array}{c}36 ; 51.3 \\
38 \%\end{array}$ & $\begin{array}{c}26 ; 51.7 \\
42 \%\end{array}$ \\
\hline $\begin{array}{l}\text { Klaver } \\
2018 \text { [141] }\end{array}$ & lamp2 & $\begin{array}{c}31 ; 60.5 \\
48 \%\end{array}$ & $\begin{array}{c}20 ; 61.8 \\
20 \%\end{array}$ & $\begin{array}{c}30 ; 62.3 \\
40 \%\end{array}$ & $\begin{array}{c}27 ; 61.5 \\
37 \%\end{array}$ \\
\hline $\begin{array}{l}\text { Dzamko }^{\text {e }} \\
2016 \text { [39] }\end{array}$ & $\begin{array}{l}\text { inflammatory } \\
\text { cytokines }\end{array}$ & 29 & 20 & 22 & 25 \\
\hline
\end{tabular}

Studies are identified by analyte(s) measured and by first author. For each study, the number of subjects in each diagnostic group, mean age for each diagnostic group, and \% males in each diagnostic group are shown. A $\beta 1-42$, amyloid-beta1-42; $\alpha$-syn, $\alpha$-synuclein; CTL, healthy control subjects without LRRK2 mutations (or, in some studies, without known PD-associated gene mutations); 5-HIAA, 5-hydroxyindolacetic acid; HSPA8, heat shock $70 \mathrm{kDa}$ protein 8; HVA, homovanillic acid; LRRK2, leucine-rich repeat kinase 2; LRRK2 CTL, healthy control subjects with PD-associated LRRK2 mutations; LRRK2 PD, PD patients with PD-associated LRRK2 mutations; mtDNA, mitochondrial DNA; Nrf2, nuclear factor (erythroid-derived 2)-like 2; p- $\alpha$-syn, phosphorylated $\alpha$-synuclein; PD, Parkinson 's disease; p-tau, phosphorylated tau; sPD, sporadic (idiopathic) PD. ${ }^{a}$ postmortem CSF from two control subjects; ${ }^{b}$ no LRRK2 CTL group; study included GBA-PD group ( $n=12$; mean age $=60.0 ; \%$ males $=67 \%) ;{ }^{c} 23$ LRRK2 CTL and 7 LRRK2 PD subjects were listed as a "LRRK2 cohort" $(n=30$, mean age $=53.1$, $\%$ males $=50 \%) ;{ }^{\mathrm{d}}$ LRRK2 gene mutation status not stated; ${ }^{\mathrm{e}}$ age and sex distribution given for serum cytokine measurements but not for subset of patients in each group from whom CSF samples were obtained.

total $\alpha$-synuclein was typically reduced and soluble oligomeric $\alpha$-synuclein was typically increased in PD vs. control CSF, neither protein could discriminate between PD and other parkinsonian syndromes [17]. The complex interactions between LRRK2 and $\alpha$ synuclein are beyond the scope of this review; they include LRRK2's effects on $\alpha$-synuclein's expression and aggregation neuron-to-neuron transmission, $\alpha$-synuclein-induced neuroinflammation, and interactions of both proteins on 14-3-3 protein and other common proteins [reviewed by Cresto et al. 2018 (105)]. 
Table 2

Summary statistics for LRRK2 CSF studies measuring A $\beta 1-42$, tau, p-tau, and $\alpha$-synuclein

\begin{tabular}{|c|c|c|c|c|}
\hline Study & sPD & $\begin{array}{l}\text { LRRK2 } \\
\text { PD }\end{array}$ & $\begin{array}{l}\text { LRRK2 } \\
\text { CTL }\end{array}$ & CTL \\
\hline \multicolumn{5}{|l|}{ A及1-42 } \\
\hline Aasly 2012 [94] & & $504(129)$ & $602(234)$ & \\
\hline Brockmann 2015 & 843.5 & 923.0 & & 1132.0 \\
\hline$[96]$ & $(372.0-1374.0)$ & $(339.0-1276.0)$ & & $(587.0-1517.0)$ \\
\hline Vilas 2016 [79] & $\begin{array}{c}217.6 \\
(168.0-284.5)\end{array}$ & $\begin{array}{c}251.2 \\
(198.6-293.3)^{\mathrm{a}}\end{array}$ & $\begin{array}{c}251.8 \\
(214.9-293.0)\end{array}$ & $\begin{array}{c}279.4 \\
(228.5-300.1)\end{array}$ \\
\hline $\begin{array}{l}\text { Podlesniy } 2016 \\
\text { [78] }\end{array}$ & $231(12)$ & $248(16)$ & $253(10)$ & $262(16)$ \\
\hline \multicolumn{5}{|l|}{ tau } \\
\hline Aasly 2012 [94] & & $24.4(22.6)$ & $36.4(32.0)$ & \\
\hline Brockmann 2015 & 170.0 & 237.0 & & 219.0 \\
\hline$[96]$ & $(49.0-346.0)$ & $(92.0-609.0)$ & & $(134.0-476.0)$ \\
\hline Vilas 2016 [79] & $\begin{array}{c}36.3 \\
(31.9-46.6)\end{array}$ & $\begin{array}{c}39.4 \\
(31.9-56.4)\end{array}$ & $\begin{array}{c}38.5 \\
(4.4-52.2)\end{array}$ & $\begin{array}{c}42.3 \\
(35.4-54.5)\end{array}$ \\
\hline $\begin{array}{l}\text { Podlesniy } 2016 \\
\text { [78] }\end{array}$ & $40(3)$ & $48(5)$ & $42(3)$ & $46(4)$ \\
\hline \multicolumn{5}{|l|}{ p-tau } \\
\hline Aasly 2012 [94] & & $16.7(3.8)$ & $21.1(9.0)$ & \\
\hline Brockmann 2015 & 32.0 & 38.0 & & 38.5 \\
\hline [96] & $(16.0-73.0)$ & $(14.0-86.0)$ & & $(31.0-76.0)$ \\
\hline Vilas [79] & $\begin{array}{c}25.0 \\
(1.4-29.6)\end{array}$ & $\begin{array}{c}27.2 \\
(24.4-31.9)\end{array}$ & $\begin{array}{c}27.8 \\
(4.4-38.3)\end{array}$ & $\begin{array}{c}28.7 \\
(2.2-35.0)\end{array}$ \\
\hline $\begin{array}{l}\text { Podlesniy } 2016 \\
\text { [78] }\end{array}$ & $27(2)$ & $30(3)$ & $29(2)$ & $30(2)$ \\
\hline \multicolumn{5}{|l|}{$\alpha$-synuclein } \\
\hline Aasly 2014 [109] & $22.8(4.2)$ & $20.5(3.1)$ & $17.8(2.6)$ & $24.7(4.5)$ \\
\hline $\begin{array}{l}\text { Podlesniy } 2016 \\
\text { [78] }\end{array}$ & $1159(51)$ & $1550(151)$ & $1364(93)$ & $1501(126)$ \\
\hline Vilas 2016 [79] & $\begin{array}{c}1015.9 \\
(853.0-1442.8)\end{array}$ & $\begin{array}{c}1475.1 \\
(1033.8-1752.2)\end{array}$ & $\begin{array}{c}1337.2 \\
(1059.1-1920.6)\end{array}$ & $\begin{array}{c}1364.5 \\
(1040.0-1785.6)\end{array}$ \\
\hline \multicolumn{5}{|c|}{$\alpha$-synuclein oligomers } \\
\hline Aasly 2014 [109] & $\begin{array}{c}80,186 \\
(23,861)\end{array}$ & $\begin{array}{l}24,510 \\
(7,161)\end{array}$ & $\begin{array}{c}38,754 \\
(12,514)\end{array}$ & $\begin{array}{l}17,117 \\
(2,943)\end{array}$ \\
\hline
\end{tabular}

Data are presented as follows: Aasly et al. 2012 [94]: mean (SD), pg/mL; Brockmann et al. 2015 [96]: median (range), pg/mL with values reported for baseline; Vilas et al. 2016 [79]: medians (interquartile range [25th:75th]), (pg/mL); Podlesniy et al. 2016 [78]: means (SEM), pg/mL; Aasly et al. 2014 [109]: mean (SEM), ng/mL for total $\alpha$-synuclein, relative luminescence units/second for soluble $\alpha$-synuclein oligomers. (The studies by Shi et al. 2012 [106] and Stewart et al. 2015 [33], both of which measured $\alpha$-synuclein, are not included in this table although they are discussed in the manuscript. Shi et al. [106] did not present summary statistics. Stewart et al. [33] did not distinguish between LRRK2 PD and LRRK2 CTL subjects in that study's LRRK2 cohort, and whether some PD subjects in the multicenter collaborative and DATATOP cohorts carried LRRK2 mutations was not stated.) SPD, sporadic Parkinson's disease; LRRK2 PD, Parkinson's disease patients with LRRK2 gene mutations; LRRK2 CTL, healthy subjects carrying PD-associated LRRK2 mutations; CTL, healthy control subjects without LRRK2 gene mutations (or, in some studies, without known PD-associated gene mutations); A $\beta 1-42$, amyloid-beta1-42; p-tau, phosphorylated tau (p-tau 181$) ; \alpha$-syn, $\alpha$-synuclein. ${ }^{a}$ Vilas et al. [79] listed the interquartile range for LRRK2 PD A $\beta 1-42$ as (198.62-93.34), which could not have been correct; the second number has been corrected to 293.34.

Five LRRK2 CSF-related studies measured total, soluble oligomeric, and/or phosphorylated $\alpha$ synuclein. Shi et al. [106] measured $\alpha$-synuclein and DJ-1 protein in LRRK2 PD and LRRK2 CTL subjects only. DJ-1 mutations have been associated with familial PD [107] and oxidation-induced inactivation of DJ-1 protein is associated with SPD [108]. The study by Shi et al. reported no signifi- cant differences between the groups for either protein, although summary statistics were not shown. Aasly et al. [109] measured total and soluble oligomeric $\alpha$-synuclein in the four diagnostic groups. No statistically significant differences were found between the groups for total $\alpha$-synuclein. Soluble oligomeric $\alpha$-synuclein levels were reported to be significantly higher in SPD and LRRK2 CTL subjects, but not 
Table 3

Summary statistics for LRRK2 CSF studies measuring oxidative stress-related proteins, autophagy proteins, pteridines, and other analytes

\begin{tabular}{|c|c|c|c|c|}
\hline Study & sPD & $\begin{array}{c}\text { LRRK2 } \\
\text { PD }\end{array}$ & $\begin{array}{c}\text { LRRK2 } \\
\text { CTL }\end{array}$ & CTL \\
\hline \multicolumn{5}{|l|}{ Oxidative stress } \\
\hline Nrf2 (Loeffler 2016) & 1.38 & 1.52 & 1.46 & 1.53 \\
\hline$[125]$ & $(1.26,1.46)$ & $(1.01,1.73)$ & $(1.36,1.61)$ & $(1.33,1.70)$ \\
\hline 8-OHdG (Loeffler 2017) & 784 & 799 & 914 & 811 \\
\hline$[127]$ & $\begin{array}{l}(543, \\
106)\end{array}$ & $\begin{array}{l}(532, \\
1189)\end{array}$ & $\begin{array}{l}(450, \\
1475)\end{array}$ & $\begin{array}{l}\text { (531, } \\
1159)\end{array}$ \\
\hline 8-ISO (Loeffler 2017) & 6.6 & 7.5 & 9.0 & 6.5 \\
\hline [127] & $(3.1,12.0)$ & $(4.4,9.8)$ & $(4.8,14.0)$ & $(3.2,16.7)$ \\
\hline TAC (Loeffler 2017) & 0.38 & 0.37 & 0.37 & 0.38 \\
\hline$[127]$ & $(0.31,0.46)$ & $(0.22,0.47)$ & $(0.23,0.45)$ & $(0.24,0.60)$ \\
\hline \multicolumn{5}{|l|}{ Autophagy proteins } \\
\hline HSPA8 (Loeffler 2016) & 0.45 & 0.34 & 0.43 & 0.41 \\
\hline$[125]$ & $(0.42,0.49)$ & $(0.22,0.51)$ & $(0.35,0.51)$ & $(0.29,0.51)$ \\
\hline Lamp2 (Klaver 2018) & 333 & 127 & 412 & 436 \\
\hline [141] & $(52.4-4542)$ & $(52.4-2047)$ & $(52.4-5695)$ & $(52.4-10,561)$ \\
\hline \multicolumn{5}{|l|}{ Pteridines } \\
\hline \multicolumn{5}{|l|}{ Biopterin } \\
\hline (Ichinose 2018) [81] & $2.0(0.1)$ & $2.8(0.3)$ & $2.6(0.2)$ & $2.1(0.2)$ \\
\hline \multicolumn{5}{|l|}{ Total Biopterin } \\
\hline (Koshiba 2011) [80] & $15.0(1.2)$ & $24.0(3.0)$ & $31.65^{\mathrm{a}}$ & \\
\hline (Ichinose 2018) [81] & $14.0(0.5)$ & $15.3(0.7)$ & $18.0(0.7)$ & $19.1(0.9)$ \\
\hline \multicolumn{5}{|l|}{ Neopterin } \\
\hline (Ichinose 2018) [81] & $17.7(1.1)$ & $23.7(3.8)$ & $17.0(1.2)$ & $14.0(1.3)$ \\
\hline \multicolumn{5}{|l|}{ Total Neopterin } \\
\hline (Koshiba 2011) [80] & $21.5(1.5)$ & $26.9(5.0)$ & $25.0^{\mathrm{a}}$ & \\
\hline (Ichinose 2018) [81] & $30.8(1.5)$ & $42.5(6.6)$ & $32.8(1.5)$ & $29.2(2.1)$ \\
\hline \multicolumn{5}{|l|}{ Dihydrobiopterin } \\
\hline (Ichinose 2018) [81] & $4.9(0.2)$ & $5.7(0.6)$ & $6.3(0.3)$ & $6.4(0.5)$ \\
\hline \multicolumn{5}{|l|}{ Tetrahydrobiopterin } \\
\hline (Ichinose 2018) [81] & $7.1(0.4)$ & $6.8(0.7)$ & $9.0(0.6)$ & $10.6(0.6)$ \\
\hline \multicolumn{5}{|l|}{ Dihydroneopterin } \\
\hline (Ichinose 2018) [81] & $13.1(1.2)$ & $18.8(5.1)$ & $15.8(1.9)$ & $15.3(1.8)$ \\
\hline \multicolumn{5}{|l|}{ Other } \\
\hline HVA (Koshiba 2011) [80] & $283(48.6)$ & $357(92.1)$ & $121^{\mathrm{a}}$ & \\
\hline \multicolumn{5}{|l|}{ 5-HIAA (Koshiba 2011) } \\
\hline [81] & $39.3(4.9)$ & $71.8(13.2)$ & $50.9^{\mathrm{a}}$ & \\
\hline \multicolumn{5}{|l|}{ Exosomal p-LRRK2 } \\
\hline (Wang 2017) [38] & 2.0 & 1.25 & 1.5 & 1.0 \\
\hline \multicolumn{5}{|l|}{ MtDNA (Podlesniy 2016) } \\
\hline$[78]$ & $18(3)$ & $54(12)$ & $27(5)$ & $33(8)$ \\
\hline VEGF (Dzamko 2016) [39] & $9.1(8.1-10.1)$ & $11.5(10.3-12.5)$ & & \\
\hline IL-8 (Dzamko 2016) [39] & $29(25-34)$ & $41(35-46)$ & & \\
\hline
\end{tabular}

Data are presented as follows: Loeffler et al. 2016 [125]: median (95\% CI), ng/mL; Loeffler et al. 2017 [127]: median (range), pg/mL; Klaver et al. 2018 [141]: median (range), pg/mL; Ichinose et al. 2018 [81]: mean (SEM), pmol/mL; Koshiba et al. 2011 [80]: mean (SEM), $\mathrm{pmol} / \mathrm{mL}$; Wang et al. 2017 [38]: pS1292-LRRK2 normalized to flotillin-1 expression, relative to the mean for all pooled samples; Podlesniy et al. 2016 [78]: mean (SEM), cell-free mtDNA copies/ $\mu$ L; Dzamko et al. 2016 [39]: mean (95\% confidence interval), pg/mL. (Shi et al. 2012 [106] measured DJ-1 but did not present summary statistics, so that study is not included in the "Other" category in the table.) Median values from Wang et al. 2017 [38] for CSF exosomal p-LRRK2 were estimated from dot plots in Fig. 3b of that study. Dzamko et al. [39] attempted to measure 32 inflammatory cytokines in CSF (four of which were below the level of detection), then compared the cytokine concentrations between SPD and LRRK2 PD patients, and between CTL and LRRK2 CTL subjects. The only data that were shown were means and confidence intervals for VEGF and IL-1 $\beta$ levels in SPD and LRRK2 PD patients, therefore those data (estimated from Fig. 1C and 1D of that study) are shown in the table. sPD, sporadic Parkinson's disease; LRRK2 PD, Parkinson's disease patients with LRRK2 gene mutations; LRRK2 CTL, healthy subjects carrying PD-associated LRRK2 mutations; CTL, healthy control subjects without LRRK2 gene mutations (or, in some studies, without known PD-associated gene mutations); Nrf2, nuclear factor (erythroid-derived 2)-like 2; 8OHdG, 8-hydroxy-2'-deoxyguanosine; 8-ISO, 8-isoprostane; TAC, Total Antioxidant Capacity; HSPA8, heat shock 70 kDa protein 8; lamp2, lysosome-associated membrane glycoprotein 2; HVA, homovanillic acid; 5-HIAA, 5-hydroxyindolacetic acid; p-LRRK2, pS1292-LRRK2; mtDNA, mitochondrial DNA; VEGF, vascular endothelial growth factor; IL-8, interleukin-8. ${ }^{a} n=2$ for Koshiba et al. [80] LRRK2 CTL group. 
in LRRK2 PD patients, than in CTL subjects. (The mean value for the LRRK2 PD group was $44 \%$ higher than that of CTL group but this difference did not achieve statistical significance, possibly because of lack of sufficient statistical power; the LRRK2 PD group, the smallest group in the study, had 13 subjects.) Although the mean $\alpha$-synuclein soluble oligomer concentration in the SPD group was more than three times that in the LRRK2 PD group, the study did not indicate if the difference in $\alpha$-synuclein soluble oligomer concentrations between these two groups was examined for statistical significance. The association between oligomeric $\alpha$-synuclein concentrations and Unified Parkinson's Disease Rating Scale (UPDRS) scores in the LRRK2 PD patients was not statistically significant. Stewart et al. [33] measured CSF phosphorylated $(\mathrm{pS} 129) \alpha$-synuclein in a "LRRK2 cohort" (whose clinical status was characterized as "very early/preclinical PD") consisting of LRRK2 CTL and LRRK2 PD subjects, as well as in two other PD cohorts whose gene mutation status was not indicated (neither cohort differentiated between sPD and PD due to LRRK2 or other gene mutations): recently diagnosed PD patients who participated in the Deprenyl and Tocopherol Antioxidative Therapy of Parkinsonism (DATATOP) study [110], and patients with moderate-to-severe PD from a multicenter collaborative cohort [111]. Results for the LRRK2 cohort were not presented separately for LRRK2 PD and LRRK2 CTL subjects. pS129- $\alpha$-synuclein concentrations were negatively correlated with UPDRS scores for individuals in the early stages of PD (the LRRK2 cohort and "early PD" DATATOP cases) but not for subjects in the later stages of PD, namely the DATATOP patients at study endpoint (i.e., when their symptoms required treatment with levodopa) and moderate-to-severe PD cases in the multicenter cohort. Vilas et al. [79] reported total $\alpha$-synuclein levels to be decreased in SPD vs. LRRK2 PD, LRRK2 CTL, and CTL subjects, with no significant differences in $\alpha$-synuclein levels between the latter three groups. The study by Podlesniy et al. [78] discussed above found total $\alpha$-synuclein in SPD patients to be significantly lower than in LRRK2 PD and CTL subjects, but not different from LRRK2 CTL subjects. (The apparent differences in results between the studies of Vilas et al. and Podlesniy et al. with regard to whether $\alpha$-synuclein levels were lower in sPD patients than in LRRK2 CTL subjects may be due to the smaller sample sizes in the latter study, because the direction of the change was the same in both studies.)
To summarize the findings for these studies: total $\alpha$-synuclein levels may be lower, and $\alpha$-synuclein soluble oligomer levels may be higher, in SPD than in LRRK2 PD.

\section{LRRK2 CSF STUDIES MEASURING OXIDATIVE STRESS-RELATED PARAMETERS}

Oxidative stress is defined as the production of reactive oxygen and nitrogen species in excess of anti-oxidant mechanisms [112]. It is present in the PD SNC [113-115] and may contribute to the loss of dopaminergic neurons in this region $[116,117]$. Multiple mechanisms are believed to be involved, including decreased local antioxidant concentrations [118], increased iron concentrations [119], production of $\mathrm{H}_{2} \mathrm{O}_{2}$ (which may be converted to hydroxyl radical via the Fenton reaction [120]) and reactive dopamine quinones as byproducts of dopamine turnover [121], and mitochondrial dysfunction [122]. A recent meta-analysis [123] found increased concentrations, in PD peripheral blood, of 8-hydroxy-2'-deoxyguanosine (8-OHdG, a marker for oxidative damage to DNA), malondialdehyde, nitrite, and ferritin, with decreased levels of the antioxidants catalase, uric acid, and glutathione. Few CSF studies were found for the meta-analysis, which indicated a non-significant association between 8OHdG and PD. Investigation of oxidative stress markers in CSF samples from LRRK2 mutationbearing individuals is of interest because the LRRK2 G2019S mutation was shown to lead to an increase in the production of intracellular reactive oxygen species in an in vitro study [124].

Two CSF studies investigated the influence of PD-associated LRRK2 mutations on oxidative stressrelated analytes. Loeffler et al. [125] found no differences between the four diagnostic groups for CSF concentrations of nuclear factor (erythroidderived 2)-like 2 (Nrf2), a major regulator of the anti-oxidant response [126], although Nrf2 levels were positively associated with total and part III (motor) UPDRS scores for LRRK2 PD patients. The same investigators subsequently compared CSF levels of 8-OHdG, 8-isoprostane (8-ISO), and total antioxidant capacity (TAC), between the four diagnostic groups [127]. 8-OHdG is a marker for oxidative damage to nuclear and mitochondrial DNA [128] and 8-ISO is a marker for peroxidation of arachidonic acid [129]. Both 8-OHdG and 8-ISO 
are accepted biomarkers for oxidative stress. TAC is a measure of the activities of non-enzymatic, low molecular weight antioxidants such as uric acid, ascorbic acid, glutathione, and $\alpha$-tocopherol [130, 131]. A decrease in TAC could predispose to oxidative damage, therefore TAC has been suggested as a possible indirect marker for oxidative stress [132]. Although 8-OHdG and 8-ISO concentrations were lower in each of the other three groups than in the LRRK2 CTL group, most $p$-values for the pairwise comparisons did not achieve statistical significance at the 0.05 level using the Dwass, Steel, CrichtlowFligner (DSCF) multiple comparison procedure. The smallest DSCF $p$-values were found for the comparison between LRRK2 CTL and SPD subjects, with $p$-values of 0.03 for $8-\mathrm{OHdG}$ and 0.06 for 8 -ISO. The differences between LRRK2 CTL and CTL subjects for 8-OHdG and 8-ISO concentrations (respective DSCF $p$-values 0.18 and 0.10 ) were similar in magnitude to those between the LRRK2 CTL and SPD groups. TAC concentrations were similar between groups. These findings suggest that CSF concentrations of oxidative stress biomarkers may not differ between SPD and LRRK2 PD patients, although they may be decreased, for unknown reasons, in LRRK2 CTL subjects.

\section{LRRK2 CSF STUDIES MEASURING OTHER ANALYTES}

CSF studies relating to wildtype LRRK2 or PD-associated LRRK2 mutations were found in which autophagy-related proteins, pteridines, proand anti-inflammatory cytokines, and total mitochondrial DNA (mtDNA) were measured. Other studies included measurement of LRRK2 protein and its autophosphorylation in CSF exosomes, and two omics-type analyses, namely a metabolomics study and "transcriptomic profiling" of CSF RNA species. The findings in these studies will be reviewed below.

The autophagy-lysosomal pathway, together with the ubiquitin-proteasome system, is responsible for removing misfolded proteins which are unable to be refolded. More than $30 \%$ of new proteins are misfolded [133]. These proteins typically have impaired biological activities and an increased likelihood of aggregating, with the risk of forming cytotoxic soluble oligomers. Three autophagic mechanisms are recognized in mammals, namely macroautophagy, chaperone-mediated autophagy (CMA), and microautophagy [134]. There is evidence for impaired autophagic mechanisms in PD [135-138]. Notably, LRRK2 is thought to play an important role in the regulation of autophagy [139]. Although wildtype LRRK2 is a substrate of (i.e., can be degraded by) CMA, G2019S LRRK2 is poorly degraded by this pathway $[49,140]$.

Two studies compared CSF concentrations of autophagy-related proteins between the four diagnostic groups. Loeffler et al. [125] measured heat shock $70 \mathrm{kDa}$ protein 8 (HSPA8) and the same investigators later measured lysosome-associated membrane glycoprotein 2 (lamp2) [141]. In CMA, HSPA8 binds to proteins with sequences which are biochemically similar to KFERQ [142]; the HSPA8-substrate protein complex then binds to lamp2a, one of lamp2's three isoforms. Binding to lamp2a is rate-limiting for CMA [143] and facilitates the translocation of the substrate protein into the lysosomal lumen, where it is rapidly degraded. CSF concentrations of HSPA8 were not found to be significantly different between the four diagnostic groups in the first study by Loeffler et al. [125]. However, in the later study [141] lamp2 levels were significantly lower in female LRRK2 PD patients than in the two control groups. (The study simultaneously investigated the effects of sex and diagnostic group on lamp2 concentrations; male LRRK2 PD patients were excluded from the statistical analysis because of their low number $[n=4]$ ). The $p$-value for the comparison of lamp2 concentrations between female LRRK2 PD patients and SPD patients was 0.06 , and the effect was in the same direction as the comparison between female LRRK2 PD patients and the control groups (LRRK2 PD females $<$ SPD). These findings suggested that CSF lamp2 levels might be decreased in female LRRK2 PD patients in comparison to SPD patients and control (LRRK2 CTL and CTL) subjects.

Pteridine is a compound composed of fused pyridine and pyrazine rings. The term "pteridines" refers to similar compounds with substitutions on these rings. The most common pteridines are 2amino-4-oxo derivatives of pteridine, known as pterins [144]. Biopterin and neopterin are fully oxidized pterins [145], while "reduced" pterins include tetrahydrobiopterin, dihydrobiopterin, and neopterin. Tetrahydrobiopterin is a cofactor for aromatic amino acid hydroxylases (phenylalanine hydroxylase, tyrosine hydroxylase, and tryptophan hydroxylase) [146], which play roles in neurotransmitter synthesis. Of relevance to PD is that tetrahydrobiopterin is an essential cofactor for tyrosine hydroxylase, the rate-limiting enzyme for dopamine synthesis [147]. Neopterin is 
produced by macrophages and is considered to be a marker of immune activation [148].

Two CSF studies have examined differences between the diagnostic groups for concentrations of pteridine compounds. Koshiba et al. [80] compared total biopterin and total neopterin between LRRK2 PD, LRRK2 CTL, and SPD subjects (however, the LRRK2 CTL group contained only two subjects). Total biopterin was defined as the sum of the concentrations of tetrahydrobiopterin, its partial oxidation product dihydrobiopterin, and its fullyoxidized product biopterin, while total neopterin was defined as the sum of dihydroneopterin and its oxidation product neopterin. Total biopterin concentrations were lower in SPD than in LRRK2 PD patients. Although normal controls were not included in the study, the mean concentration of total biopterin in LRRK2 PD patients was similar to that reported earlier for similar-aged control subjects [149]. Total neopterin did not differ significantly between SPD and LRRK2 PD patients. Ichinose et al. [81], from the same institution, later compared CSF levels of tetrahydrobiopterin, dihydrobiopterin, biopterin, total biopterin, neopterin, dihydroneopterin, and total neopterin between the four diagnostic groups. Biopterin was lower in SPD than in LRRK2 CTL and LRRK2 PD subjects. Total biopterin was significantly lower in SPD than in CTL and LRRK2 CTL subjects, and lower in LRRK2 PD than in CTL subjects. Total biopterin for the SPD group was slightly lower than for the LRRK2 PD group in this study, but in contrast to the findings by Koshiba et al. it was not significantly different between the SPD and LRRK2 PD groups. The study by Ichinose had a larger sample size for the LRRK2 PD group $(n=13)$ than the study by Koshiba et al. $(n=7)$, and the mean values for total biopterin in LRRK2 PD patients were quite different in the two studies (means \pm SEM: Ichinose et al. $15.3 \pm 0.7 \mathrm{pmol} / \mathrm{mL}$; Koshiba et al. $24.0 \pm 3.0 \mathrm{pmol} / \mathrm{mL}$ ). Tetrahydrobiopterin levels were similar between LRRK2 PD and SPD patients, but were lower in both groups than in the CTL group. Tetrahydrobiopterin in SPD patients was also lower than in LRRK2 CTL subjects. The difference in mean tetrahydrobiopterin concentrations between the LRRK2 PD and LRRK2 CTL groups (24\% decrease in LRRK2 PD) was similar to that between SPD and CTL subjects (33\% decrease in SPD). None of the pteridine concentrations were significantly different between LRRK2 CTL and CTL subjects. Neopterin in LRRK2 PD was higher than in the CTL group but was not significantly different from its concentration in the sPD and LRRK2 CTL groups. However, total neopterin in the LRRK2 PD group was higher than in the SPD and CTL groups. The mean concentration of dihydroneopterin in the study by Ichinose et al. was lower in SPD than in LRRK2 PD patients (means \pm SEMs: $s P D, 4.9 \pm 0.2 \mathrm{pmol} / \mathrm{mL}$; LRRK2 PD: $5.7 \pm 0.6 \mathrm{pmol} / \mathrm{mL}$ ) although this difference was not statistically significant. The study by Koshiba et al. also measured homovanillic acid (HVA) and 5-hydroxyindolacetic acid (5-HIAA), major metabolites of dopamine and 5-hydroxytryptamine (serotonin) respectively; elevated concentrations of these metabolites suggest increased turnover of these neurotransmitters. HVA levels were similar between LRRK2 PD and sPD patients, while 5-HIAA was higher in LRRK2 PD than in SPD patients. The findings in these two studies suggest that CSF concentrations of pteridines may differ between SPD and LRRK2 PD, while serotonin turnover (as indicated by 5-HIAA) may be less in LRRK2 PD than in SPD.

Inflammatory changes including microglial activation [150, 151], increased levels of pro-inflammatory cytokines [152], and complement activation [153, 154] are present in the PD brain. There is also evidence for peripheral inflammation in PD [155, 156] including in the gastrointestinal system [157], where changes in gut microflora (the "gastrointestinal microbiome") have been suggested to contribute to PD's pathogenesis [158]. LRRK2 has been suggested to be a regulator of inflammation [159]. Dzamko et al. [39], in the study discussed above in which serum IL-1 $\beta$ was reported to be increased in LRRK2 CTL vs. CTL subjects, also measured 32 pro- and anti-inflammatory cytokines in CSF samples from subjects in the four diagnostic groups. Between-group differences for the cytokine concentrations were compared between SPD and LRRK2 PD patients, and between CTL and LRRK2 CTL subjects. Vascular endothelial growth factor (VEGF) and interleukin-8 (IL-8) levels were found to be significantly higher in LRRK2 PD than in SPD patients (both $p<0.001$ ) whereas no differences were found between the LRRK2 CTL and CTL groups for any of the cytokines.

Mitochondrial DNA (mtDNA) encodes 13 proteins that are critical for oxidative phosphorylation [160]. Evidence for mitochondrial dysfunction has been found in both sPD [161, 162] and LRRK2 PD [163-165], but whether similar mechanisms are involved is unclear. LRRK2 mutations can alter mitochondrial fission, cytoskeleton dynamics, and trafficking, as well as mitophagy [165]. In the study 
by Podlesniy et al. [78] discussed above, CSF concentrations of total mtDNA were significantly increased in LRRK2 PD patients compared to LRRK2 CTL and sPD subjects.

As discussed above, exosomes are cell-secreted, lipid bilayer-containing vesicles found in extracellular fluids. Two studies from the same research group reported detection of LRRK2 protein in CSF exosomes. Fraser et al. [166] reported the presence of LRRK2-positive exosomes in post-mortem CSF from two control subjects. Wang et al. [38] found no differences between the four diagnostic groups for CSF exosomal concentrations of phosphorylated (pS1292) LRRK2, although the CTL group consisted of only five subjects. The lack of between-group differences for pS1292-LRRK2 in CSF exosomes, in contrast to findings discussed above for urinary exosomes (increased pS-LRRK2 levels in male LRRK2 PD patients relative to control subjects, but an opposite trend in female LRRK2 PD patients), was attributed to high levels (near or at saturation) of LRRK2 phosphorylation (at S1292) in CSF exosomes.

"Omics"-type studies involve high-throughput analyes of large numbers of molecules [167]. Two LRRK2-related CSF omics analyses were found on PubMed. Aasly et al. [168] used proton magnetic resonance spectroscopy to measure metabolites in CSF from the four diagnostic groups. However, only 16 intermediary metabolites could be reliably measured. These included energy sources and their metabolites (glucose, $\beta$-D-glucose, pyruvate, lactate, citrate, creatine, and creatinine), neutral amino acids (glutamine, alanine, valine, and leucine), hydroxybutyrate isomers, and dimethyl sulphone, a metabolite with anti-inflammatory and anti-oxidant activities [169]. No significant differences (defined by Aasly et al. as $p<0.01$ ) for any metabolite were detected between the LRRK2 CTL and CTL groups. Comparing SPD and LRRK2 PD patients, a decrease in $\beta$-D-glucose was found in the LRRK2 PD group. 2hydroxybutyrate was lower in LRRK2 PD than in LRRK2 CTL and CTL subjects, while dimethyl sulphone was increased in LRRK2 PD vs. CTL subjects. Glutamine was higher in both PD groups than in the CTL group. Hossein-Nezhad et al. [170] performed "transcriptomic profiling" of CSF RNA species on samples from PD patients and control subjects, but no information about the presence or absence of LRRK2 gene mutations was given for either group. 201 transcripts were found to be "differentially expressed" between PD and control subjects. Although no signif- icant differences in LRRK2 gene transcription were found between the PD and control subjects, downregulated transcripts that were detected in PD CSF included two long noncoding RNAs on the LRRK2 locus.

\section{DISCUSSION}

The studies reviewed in this manuscript contain three primary comparisons of analyte concentrations between the four standard diagnostic groups, namely LRRK2 PD vs. sPD, LRRK2 PD vs. LRRK2 CTL, and LRRK2 CTL vs. CTL. The comparisons will be discussed below in that order.

\section{Comparison of CSF analyte concentrations between LRRK2 PD and SPD patients}

Biopterin was reported to be higher in LRRK2 PD than in SPD patients [81], and in an earlier study by the same investigators total biopterin was reported to be higher in LRRK2 PD [80]. (No results were presented in the latter study for the individual components of total biopterin.) The possibility that LRRK2 PD patients may have higher levels of total neopterin than SPD patients was suggested in both studies. The same pattern may hold for dihydrobiopterin, neopterin, and dihydroneopterin. Because biopterin is the fully oxidized form of tetrahydrobiopterin, the finding of an increased biopterin concentration in LRRK2 PD CSF suggests that CNS oxidative stress may be greater in LRRK2 PD than in SPD, although this was not supported by the findings in the study by Loeffler et al. [127] which assessed different measures of oxidative stress (8-OHdG, 8-ISO, and TAC). An alternative explanation for the higher biopterin concentration in LRRK2 PD than in SPD CSF is that because approximately $80 \%$ of CSF biopterin is produced by nigrostriatal dopaminergic neurons [171], lower CSF biopterin in SPD patients might indicate that loss of dopaminergic neurons in SPD is more extensive in SPD than in LRRK2 PD. This was suggested by Koshiba et al. [80], who theorized that the dopaminergic deficit in LRRK2 PD might be due to dysfunction rather than to degeneration of dopaminergic neurons. A conclusion of the study by Ichinose et al. [81] was that because neopterin has been suggested to be a marker for activation of cell-mediated immunity, specifically microglial activation [172, 173], increased levels of total neopterin in LRRK2 PD might indicate an elevated inflammatory response in the LRRK2 PD brain. 
Differing results for the comparison between LRRK2 PD and sPD patients were found between the three studies which measured total $\alpha$-synuclein $[78,79,109]$. In the investigation by Aasly et al. [109], mean $\alpha$-synuclein concentrations were similar between the two groups (LRRK2 PD, $20.5 \mathrm{ng} / \mathrm{mL}$; sPD, $22.8 \mathrm{ng} / \mathrm{mL}$ ), in contrast to the studies by Podlesniy et al. [78] and Vilas et al. [79], both of which found lower total $\alpha$-synuclein concentrations in SPD than in LRRK2 PD patients. The mean concentration of $\alpha$-synuclein soluble oligomers in the study by Aasly et al. was far higher in the SPD group (80,186 relative luminescence units/second [RLU/s]) than in the LRRK2 PD group (24,510 RLU/s) but this difference apparently was not examined for statistical significance.

A $\beta 1-42$, total tau, and phosphorylated tau concentrations were compared between LRRK2 PD and sPD patients in three studies $[78,79,96]$. No statistically significant differences between the two groups were found for these analytes in any of the investigations.

With regard to analytes which were compared between LRRK2 PD and sPD patients in only one study, mtDNA [78] and 5-HIAA [80] were found to be higher in LRRK2 PD than in SPD, while $\beta$-Dglucose was reported to be lower in LRRK2 PD than in SPD [169]. The study by Klaver et al. [141] which measured lamp2 suggested that CSF levels of this protein may be Lower in LRRK2 PD patients than in sPD patients; the Tukey Kramer $p$-value for this pairwise comparison was 0.06 , with a large difference in the medians between the two groups (LRRK2 PD, $127 \mathrm{pg} / \mathrm{mL}$; sPD, $333 \mathrm{pg} / \mathrm{mL}$ ).

To summarize the findings for comparisons of CSF analyte concentrations between LRRK2 PD and SPD patients: pteridines (biopterin and/or neopterin), total $\alpha$-synuclein, soluble oligomeric $\alpha$-synuclein, mtDNA, 5-HIAA, $\beta$-D-glucose, and/or lamp2 may offer CSF biomarkers for differentiating LRRK2 PD from sPD.

\section{Comparison of CSF analyte concentrations between LRRK2 PD and LRRK2 CTL subjects}

Three studies $[78,79,94]$ compared A $\beta 1-42$, total tau, and phosphorylated tau between LRRK2 PD and LRRK2 CTL subjects. Aasly et al. [94] reported that LRRK2 PD patients had lower levels of all three proteins than LRRK2 CTL subjects, although these differences were not statistically significant, possibly because of low statistical power ( $n=8$ for the LRRK2 PD group). The other two studies (Podlesniy et al.
[78] and Vilas et al. [79]) reported similar values for the concentrations of these analytes between these two groups. A possible explanation for these results is the heterogeneous nature of LRRK2 PD neuropathology. Not all patients with this disorder have $A \beta$, tau, or $\alpha$-synuclein pathology, and the neuropathology in the LRRK2 PD patients in the reviewed studies is unknown. Even in the atypical parkinsonian disorders that are primary tauopathies, namely CBD and PSP, total and phosphorylated tau concentrations in CSF may not be elevated [174]. (Of relevance with regard to the influence of LRRK2 mutations on tau pathology is that the G2019S LRRK2 mutation has been shown to increase spreading of tau between neurons [175] and to promote tau aggregation and neurotoxicity $[176,177])$. The four studies comparing $\alpha$-synuclein levels between LRRK2 PD and LRRK2 CTL subjects [78, 79, 106, 109] found no significant pairwise differences. The apparent lack of change in the CSF concentration of $\alpha$-synuclein in LRRK2 PD differs from SPD, for which most studies have found CSF $\alpha$-synuclein to be decreased in comparison to control subjects (reviewed by Mollenhauer [178]). The lack of change in the CSF concentration of $\alpha$-synuclein in LRRK2 PD vs. LRRK2 CTL subjects may reflect the absence of LBs in some cases of LRRK2 PD [179]. Alternatively, it could be due at least in part to small sample sizes, because the studies had limited ability to detect statistical significance for between-group differences for $\alpha$-synuclein. In particular, this may have been a problem in the 2014 study by Aasly et al. [109], which had 13 LRRK2 PD patients and 20 LRRK2 CTL subjects. A power analysis for that study indicated a power of only 0.09 to detect a difference in group means of $2.7 \mathrm{ng} / \mathrm{mL}$ and a 0.66 probability of detecting a difference in group means of $10 \mathrm{ng} / \mathrm{mL}$.

Some studies did find analytes whose concentrations differed between the LRRK2 PD and LRRK2 CTL groups: 2-hydroxybutyrate (lower in LRRK2 PD than in LRRK2 CTL subjects [169]), mtDNA (higher in LRRK2 PD than in LRRK2 CTL subjects [78]), lamp2 (lower in female LRRK2 PD than in LRRK2 CTL subjects [141]), 8-ISO and 8-OHdG (both possibly lower in LRRK2 PD than in LRRK2 CTL subjects, as discussed below [127]), and total neopterin (higher in LRRK2 PD than in LRRK2 CTL in one study [81] but not in a second one [80]). The $24 \%$ decrease in LRRK2 PD vs. LRRK2 CTL subjects for tetrahydrobiopterin, examined only in the study by Ichinose et al. [81], was not statistically significant, although it may be of biological rele- 
vance. 2-hydroxybutyrate is a ketone body which possesses anti-inflammatory activity [180]. It is considered to be an early marker for insulin resistance and glucose intolerance [181] but an explanation for its decrease in LRRK2 PD vs. LRRK2 CTL CSF is lacking. The increase in mtDNA in LRRK2 PD vs. LRRK2 CTL subjects found by Podlesniy et al. [78] differed from the findings in that study for sPD vs. CTL subjects; a small but not statistically significant decrease in mtDNA was found in the sPD group, whereas an earlier study had found a significant reduction in CSF mtDNA in early-stage sPD vs. control subjects [182]. (It was because of the increase in mtDNA in LRRK2 PD but not in SPD that Podlesniy et al. [78] suggested that neurodegeneration in LRRK2 PD may occur through different mechanisms than in SPD.) The significance of the finding of lower lamp2 levels in female LRRK2 PD patients than in female LRRK2 CTL subjects [141] is unclear, because although one of lamp2's three isoforms, lamp2a, is rate-limiting for CMA, the relationship of the CSF concentration of lamp2 to lamp2a concentrations in CSF and brain is unknown. The median values for the oxidative stress markers 8-OHdG and 8-ISO were somewhat decreased in LRRK2 PD patients relative to LRRK2 CTL subjects [127] (8-OHdG: LRRK2 PD 799 pg/mL, LRRK2 CTL, 914 pg/mL; 8-ISO: LRRK2 PD, 7.5 pg/mL, LRRK2 CTL, $9.0 \mathrm{pg} / \mathrm{mL}$ ) but these differences were not statistically significant using a multiple comparison procedure. In view of the finding by the same investigators in their earlier oxidative stress study that CSF levels of the anti-oxidant response regulator Nrf2 were positively associated with UPDRS scores in LRRK2 PD patients [125], which suggested that progression of LRRK2 PD may be associated with an increase in oxidative stress), an explanation for the observed decrease, rather than an increase, in 8OHdG and 8-ISO levels in LRRK2 PD vs. LRRK2 CTL subjects is unclear.

To summarize the findings in this section: 2hydroxybutyrate, mtDNA, lamp2, and possibly 8-OHdG, 8-ISO, total neopterin, and tetrahydrobiopterin were identified as potential biomarkers for differentiating between LRRK2 PD and LRRK2 CTL subjects.

\section{Comparison of CSF analyte concentrations} between LRRK2 CTL and CTL subjects

The only analyte whose difference in concentration between the LRRK2 CTL and CTL groups was statistically significant was soluble oligomeric $\alpha$-synuclein, which was increased in LRRK2 CTL subjects [109]. As mentioned earlier soluble oligomers, rather than the fibrillary $\alpha$-synuclein which is in Lewy bodies, have been suggested to be the neurotoxic $\alpha$-synuclein species in PD $[100,183]$. The concentration of the oxidative stress marker 8-ISO was increased $38 \%$ in LRRK2 CTL subjects vs. CTL subjects (median values: LRRK2 CTL, $9.0 \mathrm{pg} / \mathrm{ml}$; CTL, $6.5 \mathrm{pg} / \mathrm{mL}$ ) but this difference was not statistically significant [127].

\section{Limitations of the reviewed studies}

Although the studies summarized in this review examined a variety of analytes, the small number of studies of each analyte (only A $\beta 42$, total tau, phosphorylated tau, and total $\alpha$-synuclein were examined in more than two studies), the limited sample sizes (particularly in the LRRK2 PD and LRRK2 CTL groups), and the methodological differences between the studies limit the conclusions that can be drawn. While a meta-analysis might clarify the nature of group differences, this approach was not feasible given the inconsistency of the types of summary data presented in the studies, the non-normal distribution of analyte concentrations, the use of varying scales of measurements for some analytes, and our inability to determine whether results in the different studies were sufficiently homogeneous to be combined for the analysis. Some studies had small group sizes $(<10$ for at least one group: $[33,38,80,94,96,106,125$, 168]). In particular, many of the studies had low numbers of LRRK2 PD patients, which limited our ability to make conclusions about that group. Low statistical power results in a lower probability of finding true differences (i.e., a high false negative rate) and a higher rate of "significant findings" due to false positives compared to adequately-powered studies. Further, some of the studies did not include all four standard diagnostic groups $[80,94,96,106,166,170]$ and/or did not indicate which pairwise comparisons were examined. The 2014 study by Aasly et al. [109] included the four groups but did not formally compare analyte concentrations between the SPD, LRRK2 PD, and LRRK2 CTL groups; each of those groups was only compared to the CTL group. Although the study by Stewart et al. [33] included SPD, LRRK2 PD, and LRRK2 CTL subjects among the LRRK2, multicenter collaborative, and DATATOP cohorts, summary statistics were not reported separately for each of the four standard diagnostic groups. Although G2019S 
was the most frequent LRRK2 mutation in these studies, half of the investigations also included samples from subjects with other LRRK2 mutations [79, 81, 94, 96, 109, 125, 127, 141]. One study used LRRK2 CTL and LRRK2 PD subjects only with the I2020T mutation [80] while in another study the types of LRRK2 mutations were not stated [33]. Whether the findings, in some studies, of different analyte concentrations between the four diagnostic groups can be generalized across different LRRK2 mutations is unknown. Age differences between groups may have been a confounding factor in some studies (mean age differences of $>8$ years between at least two diagnostic groups: [33, 79-81, 94, 109, 168]). LRRK2 PD subjects tended to be older than LRRK2 CTL subjects. There were also varying sex distributions across the study groups, which could have confounded the results.

\section{CONCLUSIONS AND FUTURE DIRECTIONS}

Consideration of the studies in this review indicates that no CSF analytes have yet been identified that can conclusively discriminate LRRK2 PD from SPD, LRRK2 PD from LRRK2 CTL, or LRRK2 CTL from CTL subjects. Some of the analytes in these studies should be investigated further for their potential as LRRK2 PD and/or LRRK2 CTL biomarkers, among them: LRRK2 PD vs. sPD: pteridines (biopterin and neopterin), $\alpha$-synuclein (total and oligomeric), mtDNA, 5-HIAA, $\beta$-D-glucose, and lamp2; LRRK2 PD vs. LRRK2 CTL: 2-hydroxybutyrate, mtDNA, lamp2, and (possibly) 8-OHdG and 8-ISO; and LRRK2 CTL vs. CTL: $\alpha$-synuclein soluble oligomers and 8-ISO. Discovery of such biomarkers might facilitate earlier diagnosis of PD in individuals carrying LRRK2 mutations, and/or provide new insights into the mechanisms responsible for the increased risk for $\mathrm{PD}$ associated with these mutations.

Neurofilament light chain (NFL) [11, 184, 185] should also be investigated as a potential LRRK2 biomarker. NFL is present in large myelinated axons; its plasma and CSF concentrations increase in proportion to the extent of axonal damage [186]. NFL levels in CSF and plasma have been suggested to differentiate PD from PSP, CBD, and MSA (its concentration is lower in $\mathrm{PD}$ than in the atypical parkinsonian syndromes) [187], but whether NFL levels in CSF or plasma differ between SPD and LRRK2 PD is unknown. Other analytes which could be investigated as possible LRRK2 PD or LRRK2 CTL biomarkers include the key macroautophagy proteins beclin 1 [188] and LC3 [189]. Lastly, it might be worthwhile to attempt to measure LRRK2-mediated phosphorylation of Rab10 in CSF, despite the earlier finding that the concentrations of the other known LRRK2 kinase product, autophosphorylated LRRK2, did not differ in CSF exosomes between PD and control subjects [38].

Future studies should attempt to avoid the methodological and reporting problems that were observed in some of the studies reviewed above. Following the Strengthening the Reporting of Observational Studies in Epidemiology (STROBE) guidelines for study reporting [190] would help readers to determine the believability of study results. The investigations should include the four diagnostic groups discussed in this review, with group sizes sufficient to provide adequate statistical power; they should employ appropriate statistical procedures, including pairwise comparisons between the groups of interest with correction for multiple comparisons; their results should be fully reported, including means, medians, SEMs (or SDs), confidence intervals, and $p$-values; they should specify the LRRK2 mutations in their study populations; they should have similar age and sex distributions across the diagnostic groups; and their methods for measuring analytes should be repeatable by other laboratories. When feasible, studies should use samples for their SPD and LRRK2 PD groups from individuals whose diagnosis of PD was subsequently confirmed by postmortem examination. To increase the likelihood of identifying LRRK2 biomarkers, the ability of combinations of analytes (for example, inflammatory cytokines and oxidative stress markers) to discriminate between the diagnostic groups could be examined. Although biomarkers for diagnosing LRRK2 PD, and for differentiating LRRK2 CTL from CTL subjects, should ideally be related to disease pathogenesis (hopefully providing new insights into mechanisms responsible for LRRK2 PD's development or progression), non-hypothesis-driven omics-type approaches might identify unique combinations of analytes whose changes in concentration in CSF or peripheral body fluids could provide a specific biological "signature" for LRRK2 PD or LRRK2 CTL subjects. (However, an important issue with regard to metabolomics (and other omics-type analyses) is the extent to which findings from different laboratories can be compared [191). Further, as suggested by Delenclos et al. [8], multiple types of biomarker approaches could be 
used in the same study, including biochemical, imaging, clinical, and genetic analyses. Once LRRK2 PD biomarkers have been identified, future studies could investigate if these or similar biomarkers can differentiate LRRK2 PD from atypical parkinsonian syndromes. The discovery of LRRK2 PD biomarkers has assumed greater importance with the recent development of disease-modifying therapies targeting patients with LRRK2 mutations [192-194].

\section{ACKNOWLEDGMENTS}

This review was funded by a generous donation to the Beaumont Foundation by Ms. Marilyn Bishop.

\section{CONFLICTS OF INTEREST}

The Mayo Clinic, JOA, and two of JOA's colleagues had a financial interest in technologies related to the PARK8 locus in familial Parkinson's disease and the LRRK2 mutation 6055G $\longrightarrow \mathrm{A}$ (Gly2019Ser) in autosomal-dominant parkinsonism, which have been licensed to Athena Diagnostics; to date, JOA has received royalties of less than US $\$ 1,500$ through the Mayo Clinic in accordance with its royalty-sharing policies. PAL is an advisor and investigator in an ongoing clinical trial of a LRRK2 inhibitor by Denali Therapeutics.

\section{REFERENCES}

[1] de Lau LM, Breteler MM (2006) Epidemiology of Parkinson's disease. Lancet Neurol 5, 525-535.

[2] Michael J Fox Foundation for Parkinson's Research, Parkinson's Disease Causes. https://www.michaeljfox. org/understanding-parkinsons/, Accessed June 24, 2018.

[3] Kordower JH, Olanow CW, Dodiya HB, Chu Y, Beach TG, Adler CH, Halliday GM, Bartus RT (2013) Disease duration and the integrity of the nigrostriatal system in Parkinson's disease. Brain 136, 2419-2431.

[4] Biomarkers Definitions Working Group (2001) Biomarkers and surrogate endpoints: Preferred definitions and conceptual framework. Clin Pharmacol Ther 69, 89-95.

[5] Haas BR, Stewart TH, Zhang J (2012) Premotor biomarkers for Parkinson's disease - a promising direction of research. Transl Neurodegener $\mathbf{1}, 11$.

[6] LeWitt PAS, Huber BR, Zhang J (2013) An update on CSF biomarkers of Parkinson's disease. In Neurodegenerative Diseases: Integrative PPPM Approach as the Medicine of the Future, Mandel S, ed. Springer, Dordrecht, pp. 161184.

[7] Magdalinou N, Lees AJ, Zetterberg H (2014) Cerebrospinal fluid biomarkers in parkinsonian conditions: An update and future directions. J Neurol Neurosurg Psychiatry 85, 1065-1075.
[8] Delenclos M, Jones DR, McLean PJ, Uitti RJ (2016) Biomarkers in Parkinson's disease: Advances and strategies. Parkinsonism Relat Disord 22(Suppl 1), S106-S110.

[9] Mollenhauer B, Caspell-Garcia CJ, Coffey CS, Taylor P, Shaw LM, Trojanowski JQ, Singleton A, Frasier M, Marek K, Galasko D, Parkinson's Progression Marker Initiative (2017) Longitudinal CSF biomarkers in patients with early Parkinson disease and healthy controls. Neurology 89, 1959-1969.

[10] Parnetti L, Gaetani L, Eusebi P, Paciotti S, Hansson O, ElAgnaf O, Mollenhauer B, Blennow K, Calabresi P (2019) CSF and blood biomarkers for Parkinson's disease. Lancet Neurol 18, 573-586.

[11] Ge F, Ding J, Liu Y, Lin H, Chang T (2018) Cerebrospinal fluid NFL in the differential diagnosis of parkinsonian disorders: A meta-analysis. Neurosci Lett 685, 35-41.

[12] Fairfoul G, McGuire LI, Pal S, Ironside JW, Neumann J, Christie S, Joachim C, Esiri M, Evetts SG, Rolinski M, Baig F, Ruffmann C, Wade-Martins R, Hu MT, Parkkinen L, Green AJ (2016) Alpha-synuclein RT-QuIC in the CSF of patients with alpha-synucleinopathies. Ann Clin Transl Neuro 3, 812-818.

[13] Groveman BR, Orrù CD, Hughson AG, Raymond LD, Zanusso G, Ghetti B, Campbell KJ, Safar J, Galasko D, Caughey B (2018) Rapid and ultra-sensitive quantitation of disease-associated $\alpha$-synuclein seeds in brain and cerebrospinal fluid by $\alpha$ Syn RT-QuIC. Acta Neuropathol Commun 6, 7.

[14] van Rumund A, Green AJE, Fairfoul G, Esselink RAJ, Bloem BR, Verbeek MM (2019) $\alpha$-Synuclein real-time quaking-induced conversion in the cerebrospinal fluid of uncertain cases of parkinsonism. Ann Neurol 85, 777-781.

[15] Jankovic J (2008) Parkinson's disease: Clinical features and diagnosis. J Neurol Neurosurg Psychiatry 79, 368376.

[16] Adler CH, Beach TG, Hentz JG, Shill HA, Caviness JN, Driver-Dunckley E, Sabbagh MN, Sue LI, Jacobson SA, Belden CM, Dugger BN (2014) Low clinical diagnostic accuracy of early vs advanced Parkinson disease: Clinicopathologic study. Neurology $\mathbf{8 3}, 406-412$.

[17] Eusebi P, Hansson O, Paciotti S, Orso M, Chiasserini D, Calabresi P, Blennow K, Parnetti L (2017) Cerebrospinal fluid biomarkers for the diagnosis and prognosis of Parkinson's disease: Protocol for a systematic review and individual participant data meta-analysis. BMJ Open 7, e018177.

[18] Van Den Eeden SK, Tanner CM, Bernstein AL, Fross RD, Leimpeter A, Bloch DA, Nelson LM (2003) Incidence of Parkinson's disease: Variation by age, gender, and race/ethnicity. Am J Epidemiol 157, 1015-1022.

[19] Singleton AB, Farrer MJ, Bonifati V (2013) The genetics of Parkinson's disease: Progress and therapeutic implications. Mov Disord 28, 14-23.

[20] Berg D, Schweitzer KJ, Leitner P, Zimprich A, Lichtner P, Belcredi P, Brüssel T, Schulte C, Maass S, Nägele T, Wszolek ZK, Gasser T (2005) Type and frequency of mutations in the LRRK2 gene in familial and sporadic Parkinson's disease. Brain 128, 3000-3011.

[21] Aasly JO, Toft M, Fernandez-Mata I, Kachergus J, Hulihan M, White LR, Farrer M (2005) Clinical features of LRRK2-associated Parkinson's disease in central Norway. Ann Neurol 57, 762-765.

[22] Goldwurm S, Zini M, Di Fonzo A, De Gaspari D, Siri C, Simons EJ, van Doeselaar M, Tesei S, Antonini A, Canesi M, Zecchinelli A, Mariani C, Meucci N, Sacilotto 
G, Cilia R, Isaias IU, Bonetti A, Sironi F, Ricca S, Oostra BA, Bonifati V, Pezzoli G (2006) LRRK2 G2019S mutation and Parkinson's disease: A clinical, neuropsychological and neuropsychiatric study in a large Italian sample. Parkinsonism Relat Disord 12, 410-419.

[23] Ferreira JJ, Guedes LC, Rosa MM, Coelho M, van Doeselaar M, Schweiger D, Di Fonzo A, Oostra BA, Sampaio C, Bonifati V (2007) High prevalence of LRRK2 mutations in familial and sporadic Parkinson's disease in Portugal. Mov Disord 22, 1194-201.

[24] Kestenbaum M, Alcalay RN (2017) Clinical features of LRRK2 carriers with Parkinson's disease. Adv Neurobiol 14, 31-48.

[25] Hernandez DG, Paisán-Ruíz C, McInerney-Leo A, Jain S, Meyer-Lindenberg A, Evans EW, Berman KF, Johnson J, Auburger G, Schäffer AA, Lopez GJ, Nussbaum RL, Singleton AB (2005) Clinical and positron emission tomography of Parkinson's disease caused by LRRK2. Ann Neurol 57, 453-456.

[26] Wszolek ZK, Pfeiffer RF, Tsuboi Y, Uitti RJ, McComb RD, Stoessl AJ, Strongosky AJ, Zimprich A, MüllerMyhsok B, Farrer MJ, Gasser T, Calne DB, Dickson DW (2004) Autosomal dominant parkinsonism associated with variable synuclein and tau pathology. Neurology 62, 16191622.

[27] Zimprich A, Biskup S, Leitner P, Lichtner P, Farrer M, Lincoln S, Kachergus J, Hulihan M, Uitti RJ, Calne DB, Stoessl AJ, Pfeiffer RF, Patenge N, Carbajal IC, Vieregge P, Asmus F, Müller-Myhsok B, Dickson DW, Meitinger T, Strom TM, Wszolek ZK, Gasser T (2004) Mutations in LRRK2 cause autosomal-dominant parkinsonism with pleomorphic pathology. Neuron 44, 601-607.

[28] Healy DG, Falchi M, O’Sullivan SS, Bonifati V, Durr A, Bressman S, Brice A, Aasly J, Zabetian CP, Goldwurm S, Ferreira JJ, Tolosa E, Kay DM, Klein C, Williams DR, Marras C, Lang AE, Wszolek ZK, Berciano J, Schapira AH, Lynch T, Bhatia KP, Gasser T, Lees AJ, Wood NW; International LRRK2 Consortium (2008) Phenotype, genotype, and worldwide genetic penetrance of LRRK2-associated Parkinson's disease: A case-control study. Lancet Neurol 7, 583-590.

[29] Hasegawa K, Stoessl AJ, Yokoyama T, Kowa H, Wszolek ZK, Yagishita S (2009) Familial parkinsonism: Study of original Sagamihara PARK8 (I2020T) kindred with variable clinicopathologic outcomes. Parkinsonism Relat Disord 15, 300-306.

[30] Greggio E, Cookson MR (2009) Leucine-rich repeat kinase 2 mutations and Parkinson's disease: Three questions. ASN Neuro 1, e00002.

[31] Tong Y, Shen J (2012) Genetic analysis of Parkinson's disease-linked leucine-rich repeat kinase 2. Biochem Soc Trans 40, 1042-1046.

[32] Wider C, Dickson DW, Wszolek ZK (2010) Leucinerich repeat kinase 2 gene-associated disease: Redefining genotype-phenotype correlation. Neurodegener Dis 7, 175-179.

[33] Stewart T, Sossi V, Aasly JO, Wszolek ZK, Uitti RJ, Hasegawa K, Yokoyama T, Zabetian CP, Leverenz JB, Stoessl AJ, Wang Y, Ginghina C, Liu C, Cain KC, Auinger P, Kang UJ, Jensen PH, Shi M, Zhang J (2015) Phosphorylated $\alpha$-synuclein in Parkinson's disease: Correlation depends on disease severity. Acta Neuropathol Commun 3, 7 .

[34] Sossi V, de la Fuente-Fernández R, Nandhagopal R, Schulzer M, McKenzie J, Ruth TJ, Aasly JO, Farrer
MJ, Wszolek ZK, Stoessl JA (2010) Dopamine turnover increases in asymptomatic LRRK2 mutations carriers. Mov Disord 25, 2717-2723.

[35] Nandhagopal R, Mak E, Schulzer M, McKenzie J, McCormick S, Sossi V, Ruth TJ, Strongosky A, Farrer MJ, Wszolek ZK, Stoessl AJ (2008) Progression of dopaminergic dysfunction in a LRRK2 kindred: A multitracer PET study. Neurology 71, 1790-1795.

[36] Fraser KB, Moehle MS, Alcalay RN, West AB; LRRK2 Cohort Consortium (2016) Urinary LRRK2 phosphorylation predicts parkinsonian phenotypes in G2019S LRRK2 carriers. Neurology 86, 994-999.

[37] Théry C, Zitvogel L, Amigorena S (2002) Exosomes: Composition, biogenesis and function. Nat Rev Immunol 2, 569-579.

[38] Wang S, Liu Z, Ye T, Mabrouk OS, Maltbie T, Aasly J, West AB (2017) Elevated LRRK2 autophosphorylation in brain-derived and peripheral exosomes in LRRK2 mutation carriers. Acta Neuropathol Commun 5, 86.

[39] Dzamko N, Rowe DB, Halliday GM (2016) Increased peripheral inflammation in asymptomatic leucine-rich repeat kinase 2 mutation carriers. Mov Disord 31, 889-897.

[40] Bakshi R, Macklin EA, Logan R, Zorlu MM, Xia N, Crotty GF, Zhang E, Chen X, Ascherio A, Schwarzschild MA (2019) Higher urate in LRRK2 mutation carriers resistant to Parkinson disease. Ann Neurol 85, 593-599.

[41] Johansen KK, Wang L, Aasly JO, White LR, Matson WR, Henchcliffe C, Beal MF, Bogdanov M (2009) Metabolomic profiling in LRRK2-related Parkinson's disease. PLoS One 4, e7551.

[42] Brockmann K, Apel A, Schulte C, Schneiderhan-Marra N, Pont-Sunyer C, Vilas D, Ruiz-Martinez J, Langkamp M, Corvol JC, Cormier F, Knorpp T, Joos TO, Gasser T, Schüle B, Aasly JO, Foroud T, Marti-Masso JF, Brice A, Tolosa E, Marras C, Berg D, Maetzler W (2016) Inflammatory profile in LRRK2-associated prodromal and clinical PD. J Neuroinflammation 13, 122.

[43] Fan Y, Howden AJM, Sarhan AR, Lis P, Ito G, Martinez TN, Brockmann K, Gasser T, Alessi DR, Sammler EM (2018) Interrogating Parkinson's disease LRRK2 kinase pathway activity by assessing Rab10 phosphorylation in human neutrophils. Biochem J 475, 23-44.

[44] English AR, Voeltz GK (2013) Rab10 GTPase regulates ER dynamics and morphology. Nat Cell Biol 15, 69-78.

[45] Ferree A, Guillily M, Li H, Smith K, Takashima A, Squillace R, Weigele M, Collins JJ, Wolozin B (2012) Regulation of physiologic actions of LRRK2: Focus on autophagy. Neurodegener Dis 10, 238-241.

[46] Gómez-Suaga P, Fdez E, Blanca Ramírez M, Hilfiker S (2012) A link between autophagy and the pathophysiology of LRRK2 in Parkinson's disease. Parkinsons Dis 2012, 324521.

[47] Li JQ, Tan L, Yu JT (2014) The role of the LRRK2 gene in Parkinsonism. Mol Neurodegener 9, 47.

[48] Rideout HJ, Stefanis L (2014) The neurobiology of LRRK2 and its role in the pathogenesis of Parkinson's disease. Neurochem Res 39, 576-592.

[49] Wallings R, Manzoni C, Bandopadhyay R (2015) Cellular processes associated with LRRK2 function and dysfunction. FEBS J 282, 2806-2826.

[50] Olszewska DA, McCarthy A, Fallon EM, Lynch T (2015) Recognising the phenotype of genetic forms of Parkinson's disease in clinical practice. ACNR 15, 5-9.

[51] Dächsel JC, Farrer MJ (2010) LRRK2 and Parkinson disease. Arch Neurol 67, 542-547. 
[52] Cookson MR (2010) The role of leucine-rich repeat kinase 2 (LRRK2) in Parkinson's disease. Nat Rev Neurosci 11, 791-797.

[53] West AB, Moore DJ, Biskup S, Bugayenko A, Smith WW, Ross CA, Dawson VL, Dawson TM (2005) Parkinson's disease-associated mutations in leucine-rich repeat kinase 2 augment kinase activity. Proc Natl Acad Sci U S A 102, 16842-16847.

[54] Lewis PA, Greggio E, Beilina A, Jain S, Baker A, Cookson MR (2007) The R1441C mutation of LRRK2 disrupts GTP hydrolysis. Biochem Biophys Res Commun 357, 668-671.

[55] Li X, Tan YC, Poulose S, Olanow CW, Huang XY, Yue $\mathrm{Z}$ (2007) Leucine-rich repeat kinase 2 (LRRK2)/PARK8 possesses GTPase activity that is altered in familial Parkinson's disease R1441C/G mutants. J Neurochem 103, 238-247.

[56] Ho DH, Jang J, Joe EH, Son I, Seo H, Seol W (2016) G2385R and I2020T Mutations Increase LRRK2 GTPase Activity. Biomed Res Int 2016, 7917128.

[57] Shu L, Zhang Y, Sun Q, Pan H, Tang B (2019) A comprehensive analysis of population differences in LRRK2 variant distribution in Parkinson's disease. Front Aging Neurosci 11, 13.

[58] Lesage S, Dürr A, Tazir M, Lohmann E, Leutenegger AL, Janin S, Pollak P, Brice A; French Parkinson's Disease Genetics Study Group (2006) LRRK2 G2019S as a cause of Parkinson's disease in North African Arabs. $N$ Engl $J$ Med 354, 422-423.

[59] Ozelius LJ, Senthil G, Saunders-Pullman R, Ohmann E, Deligtisch A, Tagliati M, Hunt AL, Klein C, Henick B, Hailpern SM, Lipton RB, Soto-Valencia J, Risch N, Bressman SB (2006) LRRK2 G2019S as a cause of Parkinson's disease in Ashkenazi Jews. N Engl J Med 354, 424-425.

[60] Orr-Urtreger A, Shifrin C, Rozovski U, Rosner S, Bercovich D, Gurevich T, Yagev-More H, Bar-Shira A, Giladi N (2007) The LRRK2 G2019S mutation in Ashkenazi Jews with Parkinson disease: Is there a gender effect? Neurology 69, 1595-1602.

[61] Kachergus J, Mata IF, Hulihan M, Taylor JP, Lincoln S, Aasly J, Gibson JM, Ross OA, Lynch T, Wiley J, Payami H, Nutt J, Maraganore DM, Czyzewski K, Styczynska M, Wszolek ZK, Farrer MJ, Toft M (2005) Identification of a novel LRRK2 mutation linked to autosomal dominant parkinsonism: Evidence of a common founder across European populations. Am J Hum Genet 76, 672-680.

[62] Clark LN, Wang Y, Karlins E, Saito L, Mejia-Santana H, Harris J, Louis ED, Cote LJ, Andrews H, Fahn S, Waters C, Ford B, Frucht S, Ottman R, Marder K (2006) Frequency of LRRK2 mutations in early- and late-onset Parkinson disease. Neurology 67, 1786-1791.

[63] Latourelle JC, Sun M, Lew MF, Suchowersky O, Klein C, Golbe LI, Mark MH, Growdon JH, Wooten GF, Watts RL, Guttman M, Racette BA, Perlmutter JS, Ahmed A, Shill HA, Singer C, Goldwurm S, Pezzoli G, Zini M, SaintHilaire MH, Hendricks AE, Williamson S, Nagle MW, Wilk JB, Massood T, Huskey KW, Laramie JM, DeStefano AL, Baker KB, Itin I, Litvan I, Nicholson G, Corbett A, Nance M, Drasby E, Isaacson S, Burn DJ, Chinnery PF, Pramstaller PP, Al-hinti J, Moller AT, Ostergaard K, Sherman SJ, Roxburgh R, Snow B, Slevin JT, Cambi F, Gusella JF, Myers RH (2008) The Gly2019Ser mutation in LRRK2 is not fully penetrant in familial Parkinson's disease: The GenePD study. BMC Med 6, 32 .

[64] Farrer MJ, Stone JT, Lin CH, Dächsel JC, Hulihan MM, Haugarvoll K, Ross OA, Wu RM (2007) Lrrk2 G2385R is an ancestral risk factor for Parkinson's disease in Asia. Parkinsonism Relat Disord 13, 89-92.

[65] Ross OA, Wu YR, Lee MC, Funayama M, Chen ML, Soto AI, Mata IF, Lee-Chen GJ, Chen CM, Tang M, Zhao Y, Hattori N, Farrer MJ, Tan EK, Wu RM (2008) Analysis of Lrrk2 R1628P as a risk factor for Parkinson's disease. Ann Neurol 64, 88-92.

[66] Rudenko IN, Kaganovich A, Hauser DN, Beylina A, Chia R, Ding J, Maric D, Jaffe H, Cookson MR (2012) The G2385R variant of leucine-rich repeat kinase 2 associated with Parkinson's disease is a partial loss-of-function mutation. Biochem J 446, 99-111.

[67] Rudenko IN, Kaganovich A, Langston RG, Beilina A, Ndukwe K, Kumaran R, Dillman AA, Chia R, Cookson MR (2017) The G2385R risk factor for Parkinson's disease enhances CHIP-dependent intracellular degradation of LRRK2. Biochem J 474, 1547-1558.

[68] Fujiwara H, Hasegawa M, Dohmae N, Kawashima A, Masliah E, Goldberg MS, Shen J, Takio K, Iwatsubo $\mathrm{T}$ (2002) alpha-Synuclein is phosphorylated in synucleinopathy lesions. Nat Cell Biol 4, 160-164.

[69] Ishizawa T, Mattila P, Davies P, Wang D, Dickson DW (2003) Colocalization of tau and alpha-synuclein epitopes in Lewy bodies. J Neuropathol Exp Neurol 62, 389-397.

[70] Steinhilb ML, Dias-Santagata D, Fulga TA, Felch DL, Feany MB (2007) Tau phosphorylation sites work in concert to promote neurotoxicity in vivo. Mol Biol Cell 18, 5060-5068.

[71] Oueslati A (2016) Implication of Alpha-Synuclein Phosphorylation at S129 in synucleinopathies: What have we learned in the last decade? J Parkinsons Dis 6, 39-51.

[72] Qing H, Wong W, McGeer EG, McGeer PL (2009) Lrrk2 phosphorylates alpha synuclein at serine 129: Parkinson disease implications. Biochem Biophys Res Commun 387, 149-152.

[73] Kawakami F, Shimada N, Ohta E, Kagiya G, Kawashima R, Maekawa T, Maruyama H, Ichikawa T (2014) Leucinerich repeat kinase 2 regulates tau phosphorylation through direct activation of glycogen synthase kinase-3ß. FEBS $J$ 281, 3-13

[74] Hamm M, Bailey R, Shaw G, Yen SH, Lewis J, Giasson BI (2015) Physiologically relevant factors influence tau phosphorylation by leucine-rich repeat kinase 2.J Neurosci Res 93, 1567-1580.

[75] Shanley MR, Hawley D, Leung S, Zaidi NF, Dave R1, Schlosser KA, Bandopadhyay R, Gerber SA, Liu M (2015) LRRK2 facilitates tau phosphorylation through strong interaction with tau and cdk5. Biochemistry 54, 51985208.

[76] Steger M, Diez F, Dhekne HS, Lis P, Nirujogi RS, Karayel O, Tonelli F, Martinez TN, Lorentzen E, Pfeffer SR, Alessi DR, Mann M (2017) Systematic proteomic analysis of LRRK2-mediated Rab GTPase phosphorylation establishes a connection to ciliogenesis. Elife 6, e31012.

[77] West AB (2017) Achieving neuroprotection with LRRK2 kinase inhibitors in Parkinson disease. Exp Neurol 298, 236-245.

[78] Podlesniy P, Vilas D, Taylor P, Shaw LM, Tolosa E, Trullas R (2016) Mitochondrial DNA in CSF distinguishes LRRK2 from idiopathic Parkinson's disease. Neurobiol Dis 94, 10-17.

[79] Vilas D, Shaw LM, Taylor P, Berg D, Brockmann K, Aasly J, Marras C, Pont-Sunyer C, Ríos J, Marek K, Tolosa E (2016) Cerebrospinal fluid biomarkers and clinical fea- 
tures in leucine-rich repeat kinase 2 (LRRK2) mutation carriers. Mov Disord 31, 906-914.

[80] Koshiba S, Tokuoka H, Yokoyama T, Horiuchi E, Ichinose $\mathrm{H}$, Hasegawa K (2011) Biopterin levels in the cerebrospinal fluid of patients with PARK8 (I2020T). J Neural Transm 118, 899-903.

[81] Ichinose H, Inoue KI, Arakawa S, Watanabe Y, Kurosaki H, Koshiba S, Hustad E, Takada M, Aasly JO (2018) Alterations in the reduced pteridine contents in the cerebrospinal fluids of LRRK2 mutation carriers and patients with Parkinson's disease. J Neural Transm 125, 45-52.

[82] Iwatsubo T, Odaka A, Suzuki N, Mizusawa H, Nukina N, Ihara Y (1994) Visualization of A beta 42(43) and A beta 40 in senile plaques with end-specific A beta monoclonals: Evidence that an initially deposited species is A beta 42(43). Neuron 13, 45-53.

[83] Mann DM, Iwatsubo T, Cairns NJ, Lantos PL, Nochlin D, Sumi SM, Bird TD, Poorkaj P, Hardy J, Hutton M, Prihar G, Crook R, Rossor MN, Haltia M (1996) Amyloid beta protein (Abeta) deposition in chromosome 14-linked Alzheimer's disease: Predominance of Abeta42(43). Ann Neurol 40, 149-156.

[84] Tapiola T, Alafuzoff I, Herukka SK, Parkkinen L, Hartikainen P, Soininen H, Pirttilä T (2009) Cerebrospinal fluid beta-amyloid 42 and tau proteins as biomarkers of Alzheimer-type pathologic changes in the brain. Arch Neurol 66, 382-389.

[85] Avila J (2006) Tau phosphorylation and aggregation in Alzheimer's disease pathology. FEBS Lett 580, 29222927.

[86] Gong CX, Liu F, Grundke-Iqbal I, Iqbal K (2005) Posttranslational modifications of tau protein in Alzheimer's disease. J Neural Transm 112, 813-838.

[87] Lindwall G, Cole RD (1984) Phosphorylation affects the ability of tau protein to promote microtubule assembly. $J$ Biol Chem 259, 5301-5305.

[88] Gong CX, Iqbal K (2008) Hyperphosphorylation of microtubule-associated protein tau: A promising therapeutic target for Alzheimer disease. Curr Med Chem 15, 2321-2328.

[89] Chai X, Dage JL, Citron M (2012) Constitutive secretion of tau protein by an unconventional mechanism. Neurobiol Dis 48, 356-366.

[90] Pooler AM, Phillips EC, Lau DH, Noble W, Hanger DP (2013) Physiological release of endogenous tau is stimulated by neuronal activity. EMBO Rep 14, 389-394.

[91] Pérez M, Medina M, Hernández F, Avila J (2018) Secretion of full-length Tau or Tau fragments in cell culture models. Propagation of Tau in vivo and in vitro. Biomol Concepts 9, 1-11.

[92] Hampel H, Bürger K, Teipel SJ, Bokde AL, Zetterberg $\mathrm{H}$, Blennow K (2008) Core candidate neurochemical and imaging biomarkers of Alzheimer's disease. Alzheimers Dement 4, 38-48.

[93] Jiménez-Jiménez FJ, Alonso-Navarro H, García-Martín E, Agúndez JA (2014) Cerebrospinal fluid biochemical studies in patients with Parkinson's disease: Toward a potential search for biomarkers for this disease. Front Cell Neurosci $\mathbf{8}, 369$.

[94] Aasly JO, Shi M, Sossi V, Stewart T, Johansen KK, Wszolek ZK, Uitti RJ, Hasegawa K, Yokoyama T, Zabetian CP, Kim HM, Leverenz JB, Ginghina C, Armaly J, Edwards KL, Snapinn KW, Stoessl AJ, Zhang J (2012) Cerebrospinal fluid amyloid $\beta$ and tau in LRRK2 mutation carriers. Neurology 78, 55-61.
[95] Shi M, Bradner J, Hancock AM, Chung KA, Quinn JF, Peskind ER, Galasko D, Jankovic J, Zabetian CP, Kim HM, Leverenz JB, Montine TJ, Ginghina C, Kang UJ, Cain KC, Wang Y, Aasly J, Goldstein D, Zhang J (2011) Cerebrospinal fluid biomarkers for Parkinson disease diagnosis and progression. Ann Neurol 69, 570-580.

[96] Brockmann K, Schulte C, Deuschle C, Hauser AK, Heger T, Gasser T, Maetzler W, Berg D (2015) Neurodegenerative CSF markers in genetic and sporadic PD: Classification and prediction in a longitudinal study. Parkinsonism Relat Disord 21, 1427-1434.

[97] Stirnemann J, Belmatoug N, Camou F, Serratrice C, Froissart R, Caillaud C, Levade T, Astudillo L, Serratrice J, Brassier A, Rose C, Billette de Villemeur T, Berger MG (2017) A review of gaucher disease pathophysiology, clinical presentation and treatments. Int J Mol Sci 18, E441.

[98] Alcalay RN, Levy OA, Waters CC, Fahn S, Ford B, Kuo SH, Mazzoni P, Pauciulo MW, Nichols WC, Gan-Or Z, Rouleau GA, Chung WK, Wolf P, Oliva P, Keutzer J, Marder K, Zhang X (2015) Glucocerebrosidase activity in Parkinson's disease with and without GBA mutations. Brain 138, 2648-2658.

[99] Wakabayashi K, Tanji K, Mori F, Takahashi H (2007) The Lewy body in Parkinson's disease: Molecules implicated in the formation and degradation of alpha-synuclein aggregates. Neuropathology 27, 494-506.

[100] Periquet M, Fulga T, Myllykangas L, Schlossmacher MG, Feany MB (2007) Aggregated alpha-synuclein mediates dopaminergic neurotoxicity in vivo. J Neurosci $\mathbf{2 7}$, 33383346.

[101] Tompkins MM, Hill WD (1997) Contribution of somal Lewy bodies to neuronal death. Brain Res 775, 24-29.

[102] McNaught KS, Shashidharan P, Perl DP, Jenner P, Olanow CW (2002) Aggresome-related biogenesis of Lewy bodies. Eur J Neurosci 16, 2136-2148.

[103] Lee SJ (2008) Origins and effects of extracellular alphasynuclein: Implications in Parkinson's disease. $\mathrm{J} \mathrm{Mol}$ Neurosci 34, 17-22.

[104] El-Agnaf OM, Salem SA, Paleologou KE, Cooper LJ, Fullwood NJ, Gibson MJ, Curran MD, Court JA, Mann DM, Ikeda S, Cookson MR, Hardy J, Allsop D (2003) Alpha-synuclein implicated in Parkinson's disease is present in extracellular biological fluids, including human plasma. FASEB J 17, 1945-1947.

[105] Cresto N, Gardier C, Gubinelli F, Gaillard MC, Liot G, West AB, Brouillet E (2019) The unlikely partnership between LRRK2 and $\alpha$-synuclein in Parkinson's disease. Eur J Neurosci 49, 339-363.

[106] Shi M, Furay AR, Sossi V, Aasly JO, Armaly J, Wang Y, Wszolek ZK, Uitti RJ, Hasegawa K, Yokoyama T, Zabetian CP, Leverenz JB, Stoessl AJ, Zhang J (2012) DJ1 and $\alpha \mathrm{SYN}$ in LRRK2 CSF do not correlate with striatal dopaminergic function. Neurobiol Aging 33, 836.e5-7.

[107] Bonifati V, Rizzu P, van Baren MJ, Schaap O, Breedveld GJ, Krieger E, Dekker MC, Squitieri F, Ibanez P, Joosse $\mathrm{M}$, van Dongen JW, Vanacore N, van Swieten JC, Brice A, Meco G, van Duijn CM, Oostra BA, Heutink P (2003) Mutations in the DJ-1 gene associated with autosomal recessive early-onset parkinsonism. Science 299, 256-259.

[108] Ariga H, Takahashi-Niki K, Kato I, Maita H, Niki T, Iguchi-Ariga SM (2013) Neuroprotective function of DJ1 in Parkinson's disease. Oxid Med Cell Longev 2013, 683920.

[109] Aasly JO, Johansen KK, Brønstad G, Warø BJ, Majbour NK, Varghese S, Alzahmi F, Paleologou KE, Amer 
DA, Al-Hayani A, El-Agnaf OM (2014) Elevated levels of cerebrospinal fluid $\alpha$-synuclein oligomers in healthy asymptomatic LRRK2 mutation carriers. Front Aging Neurosci 6, 248.

[110] Parkinson Study Group (1989) DATATOP: A multicenter controlled clinical trial in early Parkinson's disease. Arch Neurol 46, 1052-1060.

[111] Wang Y, Shi M, Chung KA, Zabetian CP, Leverenz JB, Berg D, Srulijes K, Trojanowski JQ, Lee VM, Siderowf AD, Hurtig H, Litvan I, Schiess MC, Peskind ER, Masuda M, Hasegawa M, Lin X, Pan C, Galasko D, Goldstein DS, Jensen PH, Yang H, Cain KC, Zhang J (2012) Phosphorylated $\alpha$-synuclein in Parkinson's disease. Sci Transl Med 4, $121 \mathrm{ra} 20$.

[112] Wang X, Michaelis EK (2010) Selective neuronal vulnerability to oxidative stress in the brain. Front Aging Neurosci 2,12 .

[113] Dexter DT, Holley AE, Flitter WD, Slater TF, Wells FR, Daniel SE, Lees AJ, Jenner P, Marsden CD (1994) Increased levels of lipid hydroperoxides in the parkinsonian substantia nigra: An HPLC and ESR study. Mov Disord 9, 92-97.

[114] Alam ZI, Daniel SE, Lees AJ, Marsden DC, Jenner P, Halliwell B (1997) A generalised increase in protein carbonyls in the brain in Parkinson's but not incidental Lewy body disease. J Neurochem 69, 1326-1329.

[115] Floor E, Wetzel MG (1998) Increased protein oxidation in human substantia nigra pars compacta in comparison with basal ganglia and prefrontal cortex measured with an improved dinitrophenylhydrazine assay. J Neurochem 70, 268-275.

[116] Götz ME, Freyberger A, Riederer P (1990) Oxidative stress: A role in the pathogenesis of Parkinson's disease. J Neural Transm Suppl 29, 241-249.

[117] Dias V, Junn E, Mouradian MM (2013) The role of oxidative stress in Parkinson's disease. J Parkinsons Dis 3, 461-491.

[118] Perry TL, Godin DV, Hansen S (1982) Parkinson's disease: A disorder due to nigral glutathione deficiency? Neurosci Lett 33, 305-310.

[119] Sofic E, Sapcanin A, Tahirovic I, Gavrankapetanovic I, Jellinger K, Reynolds GP, Tatschner T, Riederer P (2006) Antioxidant capacity in postmortem brain tissues of Parkinson's and Alzheimer's diseases. J Neural Transm Suppl 71, 39-43.

[120] Floyd RA, Lewis CA (1983) Hydroxyl free radical formation from hydrogen peroxide by ferrous iron-nucleotide complexes. Biochemistry 22, 2645-2649.

[121] Muñoz P, Huenchuguala S, Paris I, Segura-Aguilar J (2012) Dopamine oxidation and autophagy. Parkinsons Dis 2012, 920953.

[122] Zhu J, Chu C (2010) Mitochondrial dysfunction in Parkinson's disease. J Alzheimers Dis 20(Suppl 2), S325-S 334.

[123] Wei Z, Li X, Li X, Liu Q, Cheng Y (2018) Oxidative stress in Parkinson's disease: A systematic review and meta-analysis. Front Mol Neurosci 11, 236.

[124] Pereira C, Miguel Martins L, Saraiva L (2014) LRRK2, but not pathogenic mutants, protects against $\mathrm{H} 2 \mathrm{O} 2$ stress depending on mitochondrial function and endocytosis in a yeast model. Biochim Biophys Acta 1840, 2025-22031.

[125] Loeffler DA, Smith LM, Coffey MP, Aasly JO, LeWitt PA (2016) CSF Nrf2 and HSPA8 in Parkinson's disease patients with and without LRRK2 gene mutations. $\mathrm{J} \mathrm{Neu-}$ ral Transm 123, 179-187.
[126] Itoh K, Chiba T, Takahashi S, Ishii T, Igarashi K, Katoh Y, Oyake T, Hayashi N, Satoh K, Hatayama I, Yamamoto M, Nabeshima Y (1997) An Nrf2/small Maf heterodimer mediates the induction of phase II detoxifying enzyme genes through antioxidant response elements. Biochem Biophys Res Commun 236, 313-322.

[127] Loeffler DA, Klaver AC, Coffey MP, Aasly JO, LeWitt PA (2017) Increased oxidative stress markers in cerebrospinal fluid from healthy subjects with Parkinson's disease-associated LRRK2 gene mutations. Front Aging Neurosci 9, 89.

[128] Valavanidis A, Vlachogianni T, Fiotakis C (2009) 8-hydroxy-2' -deoxyguanosine (8-OHdG): A critical biomarker of oxidative stress and carcinogenesis. J Environ Sci Health C Environ Carcinog Ecotoxicol Rev 27, 120-139.

[129] Montuschi P, Corradi M, Ciabattoni G, Nightingale J, Kharitonov SA, Barnes PJ (1999) Increased 8-isoprostane, a marker of oxidative stress, in exhaled condensate of asthma patients. Am J Respir Crit Care Med 160, 216-220.

[130] Alho H, Leinonen JS, Erhola M, Lönnrot K, Aejmelaeus R (1998) Assay of antioxidant capacity of human plasma and CSF in aging and disease. Restor Neurol Neurosci 12, 159-165.

[131] Bartosz G (2003) Total antioxidant capacity. Adv Clin Chem 37, 219-292.

[132] Mandrioli J, Del Rio D, Zini A, Nichelli P, Merelli E, Beltrami D, Cesari C, Pellegrini N, Brighenti F, Sola P (2006) Total antioxidant capacity of cerebrospinal fluid is decreased in patients with motor neuron disease. Neurosci Lett 401, 203-208.

[133] Schubert U, Antón LC, Gibbs J, Norbury CC, Yewdell JW, Bennink JR (2000) Rapid degradation of a large fraction of newly synthesized proteins by proteasomes. Nature 404, 770-774.

[134] Orenstein SJ, Cuervo AM (2010) Chaperone-mediated autophagy: Molecular mechanisms and physiological relevance. Semin Cell Dev Biol 21, 719-726.

[135] Cuervo AM, Stefanis L, Fredenburg R, Lansbury PT, Sulzer D (2004) Impaired degradation of mutant alphasynuclein by chaperone-mediated autophagy. Science $\mathbf{3 0 5}$, 1292-1295.

[136] Alvarez-Erviti L, Rodriguez-Oroz MC, Cooper JM, Caballero C, Ferrer I, Obeso JA, Schapira AH (2010) Chaperone-mediated autophagy markers in Parkinson disease brains. Arch Neurol 67, 1464-1472.

[137] Xilouri M, Stefanis L (2011) Autophagic pathways in Parkinson disease and related disorders. Expert Rev Mol Med 13, e8.

[138] Karabiyik C, Lee MJ, Rubinsztein DC (2017) Autophagy impairment in Parkinson's disease. Essays Biochem 61, 711-720.

[139] Mamais A, Manzoni C, Nazish I, Arber C, Sonustun B, Wray S, Warner TT, Cookson MR, Lewis PA, Bandopadhyay R (2018) Analysis of macroautophagy related proteins in G2019S LRRK2 Parkinson's disease brains with Lewy body pathology. Brain Res 1701, 75-84.

[140] Orenstein SJ, Kuo SH, Tasset I, Arias E, Koga H, Fernandez-Carasa I, Cortes E, Honig LS, Dauer W, Consiglio A, Raya A, Sulzer D, Cuervo AM (2013) Interplay of LRRK2 with chaperone-mediated autophagy. $\mathrm{Nat} \mathrm{Neu-}$ rosci 16, 394-406.

[141] Klaver AC, Coffey MP, Aasly JO, Loeffler DA (2018) CSF lamp2 concentrations are decreased in female Parkinson's 
disease patients with LRRK2 mutations. Brain Res 1683, 12-16.

[142] Dice JF, Terlecky SR, Chiang HL, Olson TS, Isenman LD, Short-Russell SR, Freundlieb S, Terlecky LJ (1990) A selective pathway for degradation of cytosolic proteins by lysosomes. Semin Cell Biol 1, 449-455.

[143] Cuervo AM, Dice JF (2000) Regulation of lamp2a levels in the lysosomal membrane. Traffic 1, 570-583.

[144] Daubner SC, Fitzpatrick PF (2013) Pteridines. In Encyclopedia of Biological Chemistry, Second Edition, Lennarz W, Lane M, eds. Elsevier, Amsterdam, pp. 666-669.

[145] Guibal P, Lévêque N, Doummar D, Giraud N, Roze E, Rodriguez D, Couderc R, Billette De Villemeur T, Moussa F (2014) Simultaneous determination of all forms of biopterin and neopterin in cerebrospinal fluid. ACS Chem Neurosci 5, 533-541.

[146] Fitzpatrick PF (2000) The aromatic amino acid hydroxylases. Adv Enzymol Relat Areas Mol Biol 74, 235-294.

[147] LeWitt PA, Miller LP, Newman RP, Burns RS, Insel T, Levine RA, Lovenberg W, Calne DB (1984) Tyrosine hydroxylase cofactor (tetrahydrobiopterin) in Parkinsonism. Adv Neurol 40, 459-462.

[148] Spencer ME, Jain A, Matteini A, Beamer BA, Wang NY, Leng SX, Punjabi NM, Walston JD, Fedarko NS (2010) Serum levels of the immune activation marker neopterin change with age and gender and are modified by race, BMI, and percentage of body fat. J Gerontol A Biol Sci Med Sci 65, 858-865.

[149] Fujishiro K, Hagihara M, Takahashi A, Nagatsu T (1990) Concentrations of neopterin and biopterin in the cerebrospinal fluid of patients with Parkinson's disease. Biochem Med Metab Biol 44, 97-100.

[150] McGeer PL, Itagaki S, Boyes BE, McGeer EG (1988) Reactive microglia are positive for HLA-DR in the substantia nigra of Parkinson's and Alzheimer's disease brains. Neurology 38, 1285-1291.

[151] Gerhard A, Pavese N, Hotton G, Turkheimer F, Es M, Hammers A, Eggert K, Oertel W, Banati RB, Brooks DJ (2006) In vivo imaging of microglial activation with [11C](R)-PK11195 PET in idiopathic Parkinson's disease. Neurobiol Dis 21, 404-412.

[152] Mogi M, Harada M, Riederer P, Narabayashi H, Fujita K, Nagatsu T (1994) Tumor necrosis factor-alpha (TNFalpha) increases both in the brain and in the cerebrospinal fluid from parkinsonian patients. Neurosci Lett 165, 208210.

[153] Yamada T, McGeer PL, McGeer EG (1992) Lewy bodies in Parkinson's disease are recognized by antibodies to complement proteins. Acta Neuropathol 84, 100-104.

[154] Loeffler DA, Camp DM, Conant SB (2006) Complement activation in the Parkinson's disease substantia nigra: An immunocytochemical study. J Neuroinflammation 3, 29.

[155] Reale M, Iarlori C, Thomas A, Gambi D, Perfetti B, Di Nicola M, Onofrj M (2009) Peripheral cytokines profile in Parkinson's disease. Brain Behav Immun 23, 55-63.

[156] Qin XY, Zhang SP, Cao C, Loh YP, Cheng Y (2016) Aberrations in peripheral inflammatory cytokine levels in Parkinson disease: A systematic review and meta-analysis. JAMA Neurol 73, 1316-1324.

[157] Rolli-Derkinderen M, Leclair-Visonneau L, Bourreille A, Coron E, Neunlist M, Derkinderen P (2019) Is Parkinson's disease a chronic low-grade inflammatory bowel disease? J Neurol. doi: 10.1007/s00415-019-09321-0
[158] Lubomski M, Tan AH, Lim SY, Holmes AJ, Davis RL, Sue CM (2019) Parkinson's disease and the gastrointestinal microbiome. J Neurol. doi: 10.1007/s00415-019-09320-1

[159] Russo I, Bubacco L, Greggio E (2014) LRRK2 and neuroinflammation: Partners in crime in Parkinson's disease? J Neuroinflammation 11, 52.

[160] Gustafsson CM, Falkenberg M1, Larsson NG (2016) Maintenance and expression of mammalian mitochondrial DNA. Annu Rev Biochem 85, 133-160.

[161] Moon HE, Paek SH (2015) Mitochondrial dysfunction in Parkinson's disease. Exp Neurobiol 24, 103-116.

[162] Park JS, Davis RL, Sue CM (2018) Mitochondrial dysfunction in Parkinson's disease: New mechanistic insights and therapeutic perspectives. Curr Neurol Neurosci Rep 18, 21.

[163] Mortiboys H, Johansen KK, Aasly JO, Bandmann O (2010) Mitochondrial impairment in patients with Parkinson disease with the G2019S mutation in LRRK2. Neurology 75, 2017-2020.

[164] Papkovskaia TD, Chau KY, Inesta-Vaquera F, Papkovsky DB, Healy DG, Nishio K, Staddon J, Duchen MR, Hardy J, Schapira AH, Cooper JM (2012) G2019S leucine-rich repeat kinase 2 causes uncoupling protein-mediated mitochondrial depolarization. Hum Mol Genet 21, 4201-4213.

[165] Singh A, Zhi L1 Zhang H (2019) LRRK2 and mitochondria: Recent advances and current views. Brain Res 1702, 96-104.

[166] Fraser KB, Moehle MS, Daher JP, Webber PJ, Williams JY, Stewart CA, Yacoubian TA, Cowell RM, Dokland T, Ye T, Chen D, Siegal GP, Galemmo RA, Tsika E, Moore DJ, Standaert DG, Kojima K, Mobley JA, West AB (2013) LRRK2 secretion in exosomes is regulated by 14-3-3. Hum Mol Genet 22, 4988-5000.

[167] Hasin Y, Seldin M, Lusis A (2017) Multi-omics approaches to disease. Genome Biol 18, 83 .

[168] Aasly JO, Sæther O, Johansen KK, Bathen TF, Giskeødegård GF, White LR (2015) Changes to intermediary metabolites in sporadic and LRRK2 Parkinson's disease demonstrated by proton magnetic resonance spectroscopy. Parkinsons Dis 2015, 264896.

[169] Beilke MA, Collins-Lech C, Sohnle PG (1987) Effects of dimethyl sulfoxide on the oxidative function of human neutrophils. J Lab Clin Med 110, 91-96.

[170] Hossein-Nezhad A, Fatemi RP, Ahmad R, Peskind ER, Zabetian CP, Hu SC, Shi M, Wahlestedt C, Zhang J, Faghihi MA (2016) Transcriptomic profiling of extracellular RNAs present in cerebrospinal fluid identifies differentially expressed transcripts in Parkinson's disease. J Parkinsons Dis 6, 109-117.

[171] Levine RA, Miller LP, Lovenberg W (1981) Tetrahydrobiopterin in striatum: Localization in dopamine nerve terminals and role in catecholamine synthesis. Science 214, 919-921.

[172] Furukawa Y, Nishi K, Kondo T, Tanabe K, Mizuno Y (1992) Significance of CSF total neopterin and biopterin in inflammatory neurological diseases. J Neurol Sci 111, 65-72.

[173] Kuehne LK, Reiber H, Bechter K, Hagberg L, Fuchs D (2013) Cerebrospinal fluid neopterin is brain-derived and not associated with blood-CSF barrier dysfunction in non-inflammatory affective and schizophrenic spectrum disorders. J Psychiatr Res 47, 1417-1422.

[174] Cicognola C, Brinkmalm G, Wahlgren J, Portelius E, Gobom J, Cullen NC, Hansson O, Parnetti L, Constantinescu R, Wildsmith K, Chen HH, Beach TG, Lashley 
T, Zetterberg H, Blennow K, Höglund K (2019) Novel tau fragments in cerebrospinal fluid: Relation to tangle pathology and cognitive decline in Alzheimer's disease. Acta Neuropathol 137, 279-296.

[175] Nguyen APT, Daniel G, Valdés P, Islam MS, Schneider BL, Moore DJ (2018) G2019S LRRK2 enhances the neuronal transmission of tau in the mouse brain. Hum Mol Genet 27, 120-134.

[176] Guerreiro PS, Gerhardt E, Lopes da Fonseca T, Bähr M, Outeiro TF, Eckermann K (2016) LRRK2 promotes tau accumulation, aggregation and release. Mol Neurobiol 53, 3124-3135.

[177] Bardai FH, Ordonez DG, Bailey RM, Hamm M, Lewis J, Feany MB (2018) Lrrk promotes tau neurotoxicity through dysregulation of actin and mitochondrial dynamics. PLoS Biol 16, e2006265.

[178] Mollenhauer B (2014) Quantification of $\alpha$-synuclein in cerebrospinal fluid: How ideal is this biomarker for Parkinson's disease? Parkinsonism Relat Disord 20(Suppl 1), S76-S79.

[179] Kalia LV, Lang AE, Hazrati LN, Fujioka S, Wszolek ZK, Dickson DW, Ross OA, Van Deerlin VM, Trojanowski JQ, Hurtig HI, Alcalay RN, Marder KS, Clark LN, Gaig C, Tolosa E, Ruiz-Martínez J, Marti-Masso JF, Ferrer I, López de Munain A, Goldman SM, Schüle B, Langston JW, Aasly JO, Giordana MT, Bonifati V, Puschmann A, Canesi M, Pezzoli G, Maues De Paula A, Hasegawa K, Duyckaerts C, Brice A, Stoessl AJ, Marras C (2015) Clinical correlations with Lewy body pathology in LRRK2-related Parkinson disease. JAMA Neurol 72, 100-105.

[180] Youm YH, Nguyen KY, Grant RW, Goldberg EL, Bodogai M, Kim D, D'Agostino D, Planavsky N, Lupfer C, Kanneganti TD, Kang S, Horvath TL, Fahmy TM, Crawford PA, Biragyn A, Alnemri E, Dixit VD (2015) The ketone metabolite $\beta$-hydroxybutyrate blocks NLRP3 inflammasome-mediated inflammatory disease. Nat Med 21, 263-269.

[181] Gall WE, Beebe K, Lawton KA, Adam KP, Mitchell MW, Nakhle PJ, Ryals JA, Milburn MV, Nannipieri M, Camastra S, Natali A, Ferrannini E; RISC Study Group (2010) alpha-hydroxybutyrate is an early biomarker of insulin resistance and glucose intolerance in a nondiabetic population. PLoS One 5, e10883.

[182] Pyle A, Brennan R, Kurzawa-Akanbi M, Yarnall A, Thouin A, Mollenhauer B, Burn D, Chinnery PF, Hudson G (2015) Reduced cerebrospinal fluid mitochondrial DNA is a biomarker for early-stage Parkinson's disease. Ann Neurol 78, 1000-1004.

[183] Winner B, Jappelli R, Maji SK, Desplats PA, Boyer L, Aigner S, Hetzer C, Loher T, Vilar M, Campioni S, Tzitzilonis C, Soragni A, Jessberger S, Mira H, Consiglio A, Pham E, Masliah E, Gage FH, Riek R (2011) In vivo demonstration that alpha-synuclein oligomers are toxic. Proc Natl Acad Sci U S A 108, 4194-4199.
[184] Magdalinou NK, Paterson RW, Schott JM, Fox NC, Mummery C, Blennow K, Bhatia K, Morris HR, Giunti P, Warner TT, de Silva R, Lees AJ, Zetterberg H (2015) A panel of nine cerebrospinal fluid biomarkers may identify patients with atypical parkinsonian syndromes. J Neurol Neurosurg Psychiatry 86, 1240-1247.

[185] Herbert MK, Aerts MB, Beenes M, Norgren N, Esselink RA, Bloem BR, Kuiperij HB, Verbeek MM (2015) CSF neurofilament light chain but not FLT3 ligand discriminates Parkinsonian disorders. Front Neurol 6, 91.

[186] Gaetani L, Blennow K, Calabresi P, Di Filippo M, Parnetti L, Zetterberg H (2019) Neurofilament light chain as a biomarker in neurological disorders. J Neurol Neurosurg Psychiatry. doi: 10.1136/jnnp-2018-320106

[187] Hall S, Öhrfelt A, Constantinescu R, Andreasson U, Surova Y, Bostrom F, Nilsson C, Håkan W, Decraemer H, Någga K, Minthon L, Londos E, Vanmechelen E, Holmberg B, Zetterberg H, Blennow K, Hansson O (2012) Accuracy of a panel of 5 cerebrospinal fluid biomarkers in the differential diagnosis of patients with dementia and/or parkinsonian disorders. Arch Neurol 69, 1445-1452.

[188] Kang R, Zeh HJ, Lotze MT, Tang D (2011) The Beclin 1 network regulates autophagy and apoptosis. Cell Death Differ 18, 571-580.

[189] Sugawara K, Suzuki NN, Fujioka Y, Mizushima N, Ohsumi Y, Inagaki F (2004) The crystal structure of microtubule-associated protein light chain 3 , a mammalian homologue of Saccharomyces cerevisiae Atg8. Genes Cells 9, 611-618.

[190] von Elm E, Altman DG, Egger M, Pocock SJ, Gøtzsche PC, Vandenbroucke JP; STROBE Initiative (2007) The Strengthening the Reporting of Observational Studies in Epidemiology (STROBE) statement: Guidelines for reporting observational studies. Ann Intern Med 147, 573 577.

[191] Siskos AP, Jain P, Römisch-Margl W, Bennett M, Achaintre D, Asad Y, Marney L, Richardson L, Koulman A, Griffin JL, Raynaud F, Scalbert A, Adamski J, Prehn C, Keun HC (2017) Interlaboratory reproducibility of a targeted metabolomics platform for analysis of human serum and plasma. Anal Chem 89, 656-665.

[192] Melrose HL (2015) LRRK2 and ubiquitination: Implications for kinase inhibitor therapy. Biochem J 470, e21-4.

[193] Volpicelli-Daley LA, Abdelmotilib H, Liu Z, Stoyka L, Daher JP, Milnerwood AJ, Unni VK, Hirst WD, Yue Z, Zhao HT, Fraser K, Kennedy RE, West AB (2016) G2019S-LRRK2 expression augments $\alpha$-synuclein sequestration into inclusions in neurons. $J$ Neurosci 36, 7415-7427.

[194] Atashrazm F, Dzamko N (2016) LRRK2 inhibitors and their potential in the treatment of Parkinson's disease: Current perspectives. Clin Pharmacol 8, 177-189. 